\title{
Differential column measurements using compact solar-tracking spectrometers
}

\author{
Jia Chen ${ }^{1, a}$, Camille Viatte ${ }^{2}$, Jacob K. Hedelius ${ }^{2}$, Taylor Jones ${ }^{1}$, Jonathan E. Franklin ${ }^{1}$, Harrison Parker ${ }^{3}$, Elaine \\ W. Gottlieb ${ }^{1}$, Paul O. Wennberg ${ }^{2}$, Manvendra K. Dubey ${ }^{3}$, and Steven C. Wofsy ${ }^{1}$ \\ ${ }^{1}$ School of Engineering and Applied Sciences and Department of Earth and Planetary Sciences, Harvard University, \\ Cambridge, MA 02138, USA \\ ${ }^{2}$ Division of Geological and Planetary Sciences, California Institute of Technology, Pasadena, CA 91125, USA \\ ${ }^{3}$ Earth and Environmental Sciences, Los Alamos National Laboratory, Los Alamos, NM 87545, USA \\ a now at: Electrical and Computer Engineering, Technische Universität München, Munich, 80333, Germany \\ Correspondence to: Jia Chen (jia.chen@tum.de)
}

Received: 29 December 2015 - Published in Atmos. Chem. Phys. Discuss.: 17 February 2016

Revised: 6 June 2016 - Accepted: 8 June 2016 - Published: 12 July 2016

\begin{abstract}
We demonstrate the use of compact solar-tracking Fourier transform spectrometers (Bruker EM27/SUN) for differential measurements of the column-averaged dry-air mole fractions of $\mathrm{CH}_{4}$ and $\mathrm{CO}_{2}$ within urban areas. Using Allan variance analysis, we show that the differential column measurement has a precision of $0.01 \%$ for $X_{\mathrm{CO}_{2}}$ and $X_{\mathrm{CH}_{4}}$ with an optimum integration time of $10 \mathrm{~min}$, corresponding to Allan deviations of $0.04 \mathrm{ppm}$ and $0.2 \mathrm{ppb}$, respectively. The sensor system is very stable over time and after relocation across the continent. We report tests of the differential column measurement, and its sensitivity to emission sources, by measuring the downwind-minus-upwind column difference $\Delta X_{\mathrm{CH}_{4}}$ across dairy farms in the Chino area, California, and using the data to verify emissions reported in the literature. Ratios of spatial column differences $\Delta X_{\mathrm{CH}_{4}} / \Delta X_{\mathrm{CO}_{2}}$ were observed across Pasadena within the Los Angeles basin, indicating values consistent with regional emission ratios from the literature. Our precise, rapid measurements allow us to determine significant short-term variations $(5-10 \mathrm{~min})$ of $X_{\mathrm{CO}_{2}}$ and $X_{\mathrm{CH}_{4}}$ and to show that they represent atmospheric phenomena.

Overall, this study helps establish a range of new applications for compact solar-viewing Fourier transform spectrometers. By accurately measuring the small differences in integrated column amounts across local and regional sources, we directly observe the mass loading of the atmosphere due to the influence of emissions in the intervening locale. The inference of the source strength is much more direct than in-
\end{abstract}

version modeling using only surface concentrations and less subject to errors associated with small-scale transport phenomena.

\section{Introduction}

Cities and their surrounding urban regions occupy less than $3 \%$ of the global land surface (Grimm et al., 2008) but are home to $54 \%$ of the world population (WHO, 2014) and account for more than $70 \%$ of global fossil-fuel $\mathrm{CO}_{2}$ emissions (Gurney et al., 2015). Hence, accurate methods for measuring urban- and regional-scale carbon fluxes are required in order to design and implement policies for emission reduction initiatives.

It is challenging to use in situ measurements of $\mathrm{CO}_{2}$ and $\mathrm{CH}_{4}$ to derive emission fluxes in urban regions. Surface concentrations typically have high variance due to the influence of nearby sources, and they are strongly modulated by mesoscale transport phenomena that are difficult to simulate in atmospheric models. These include the variation of the depth of the planetary boundary layer (PBL), sea breeze, topographic flows, etc. (McKain et al., 2012; Bréon et al., 2015).

The mass loading of the atmosphere can be directly determined by measuring the column-integrated amount of a tracer through the whole atmosphere. Column measurements are insensitive to vertical redistribution of tracer mass, e.g., 
due to growth of the PBL, and are also less influenced by nearby point sources whose emissions are concentrated in a thin layer near the surface. Column observations are more compatible with the scale of atmospheric models and hence provide stronger constraints for inverse modeling (Lindenmaier et al., 2014).

One potential drawback, however, is that column observations are sensitive to surface emissions over a very wide range of spatial scales, spanning nearby emissions and all those upwind in the urban, continental, and hemispheric domains. In this paper we demonstrate how to use simultaneous measurements of the column-averaged dry-air mole fractions (DMFs) of $\mathrm{CH}_{4}$ and $\mathrm{CO}_{2}$ (denoted by $X_{\mathrm{CH}_{4}}$ and $X_{\mathrm{CO}_{2}}$, respectively) at upwind and downwind sites to mitigate this limitation. The horizontal gradients within a region are relatively insensitive to surface fluxes upwind of the domain, providing favorable input for regional flux inversions.

We use three matched, compact Fourier transform spectrometers (FTSs) to measure the small $(0.1 \%)$ differences of $X_{\mathrm{CH}_{4}}$ and $X_{\mathrm{CO}_{2}}$, and we demonstrate sufficient precision and speed to determine emission rates at the urban scale. By directly measuring spatial and temporal gradients of the mass loading, we reduce the sensitivity of inverse model results to atmospheric fine structure, such as may arise from vertical redistribution of trace gases, and that often complicates the interpretation of surface in situ data (Chang et al., 2014).

Our ground-based network of spectrometers measuring gradients of column amounts could enable new approaches to validate the urban-rural gradients of satellite observations such as OCO-2 (Crisp et al., 2008; Frankenberg et al., 2015) and TROPOMI (Veefkind et al., 2012). In contrast to the large, high-spectral-resolution instruments of the Total Carbon Column Observing Network (TCCON), which are not easily relocated, the compact spectrometers can be deployed directly under satellite tracks that pass near major cities to assess potential artifacts in satellite-derived tracer gradients that might arise from urban-rural differences in aerosol burden, land surface properties, etc.

Several recent papers have studied column-averaged concentrations of trace gases to derive source fluxes. Wunch et al. (2009) observed diurnal patterns for $X_{\mathrm{CO}_{2}}, X_{\mathrm{CH}_{4}}$, and $X_{\mathrm{CO}}$ over Los Angeles, similar to the model simulations of McKain et al. (2012) for Salt Lake City. Kort et al. (2012) used GOSAT satellite data to measure the difference between $\mathrm{CO}_{2}$ columns inside and outside Los Angeles and to derive a top-down inventory for $\mathrm{CO}_{2}$. Papers by Stremme et al. (2009, 2013) and Té et al. (2012) used total column measurements from a ground-based FTS to estimate and monitor CO emission in Mexico City and Paris, respectively. Mellqvist et al. (2010) studied plumes from industrial complexes, and Lindenmaier et al. (2014) examined plumes from two power plants and discriminated them. Kort et al. (2014) quantified large methane sources missing in inventories at Four Corners, New Mexico. However, these studies did not have simulta- neous upwind and downwind column data, one of the novel elements of the present paper.

Frey et al. (2015) and Hase et al. (2015) reported deployments of multiple FTSs of the same type as employed here, deriving calibration and stability characteristics in a field setting. We extend this analysis by determining the Allan variances of column concentration differences between spectrometer pairs deployed side-by-side, providing a rigorous assessment of the precision of the differential column measurements.

Here we study local-scale gradients in $X_{\mathrm{CO}_{2}}$ and $X_{\mathrm{CH}_{4}}$ in two applications. First, we deployed our spectrometers upwind and downwind of the dairy farms in Chino, California (about $50 \mathrm{~km}^{2}$ area), and use the data to compare with emissions reported in the literature. A second application uses the observed ratio of differences in $X_{\mathrm{CO}_{2}}$ and $X_{\mathrm{CH}_{4}}$, i.e., $\Delta X_{\mathrm{CH}_{4}} / \Delta X_{\mathrm{CO}_{2}}$, to characterize emission ratios for these gases within the Los Angeles basin.

In another application of the compact spectrometers, we co-located spectrometers to demonstrate measurement of short-term (5-10 min) variations of column-averaged DMFs in the atmosphere. The high-precision measurements with rapid scan rates are an advantage of the compact spectrometers compared to larger, higher-spectral-resolution spectrometers that have scan durations in the minute range. We show that high-frequency observations can be used to quantify the influence of sporadic events, such as plumes, transient peaks, or instabilities across the top of the mixed layer (ML), on measurements in urban areas.

\section{Differential column network}

\subsection{Column measurement and existing FTS network}

Solar-tracking FTSs can be used to measure the gas column number densities, i.e., the number of gas molecules per unit area in the atmospheric column (column $_{\mathrm{G}}$, unit: molec. $\mathrm{m}^{-2}$ ). The sun is used as light source and the FTS is located on the ground for measuring the solar radiation transmitted through the atmosphere. The recorded sun radiation spectrum is broadband and covers the absorption fingerprints of diverse gas species including $\mathrm{CO}_{2}, \mathrm{CH}_{4}, \mathrm{H}_{2} \mathrm{O}$, and $\mathrm{O}_{2}$. The attenuation of the solar intensity at specific frequencies provides a measure for the column number density of various gases. For further details of modeling the atmospheric transmittance spectrum, please see Wunch et al. (2011) and Hase et al. (2004); for the working principles of FTS please refer to Davis et al. (2001) and Griffiths and De Haseth (2007).

The existing FTS networks include NDACC (Network for the Detection of Atmospheric Composition Change; Hannigan, 2011) and TCCON (Toon et al., 2009; Wunch et al., 2010, 2011). NDACC measures at mid-infrared wavelengths and detects atmospheric $\mathrm{O}_{3}, \mathrm{HNO}_{3}, \mathrm{HCl}, \mathrm{HF}, \mathrm{CO}, \mathrm{N}_{2} \mathrm{O}$, $\mathrm{CH}_{4}, \mathrm{HCN}, \mathrm{C}_{2} \mathrm{H}_{6}$, and $\mathrm{ClONO}_{2}$, chosen to help understand 
the physical and chemical state of the upper troposphere and the stratosphere. The TCCON network focuses on column measurements of greenhouse gases, mainly $\mathrm{CO}_{2}, \mathrm{CH}_{4}, \mathrm{~N}_{2} \mathrm{O}$, and $\mathrm{CO}$, at near-infrared wavelengths. It uses the Bruker IFS $125 \mathrm{HR}$ spectrometer that is large in dimension (container size) and heavyweight ( $>500 \mathrm{~kg}$; Bruker, 2006). The spectra in the TCCON network are recorded with a spectral resolution of approx. $0.02 \mathrm{~cm}^{-1}$ and require about $170 \mathrm{~s}$ for one forward/backward scan pair (Hedelius et al., 2016).

\subsection{Differential column measurement with compact FTS}

Our differential column network uses at least two spectrometers to make simultaneous measurements of column number densities of $\mathrm{CO}_{2}, \mathrm{CH}_{4}$, and $\mathrm{O}_{2}$. We then compute the column-averaged DMFs (Wunch et al., 2011) for each gas G, i.e.,

$X_{\mathrm{G}}=\frac{\text { column }_{\mathrm{G}}}{\text { column }_{\mathrm{O}_{2}}} \cdot 0.2095$,

and differences, i.e.,

$\Delta X_{\mathrm{G}}=X_{\mathrm{G}}^{\mathrm{d}}-X_{\mathrm{G}}^{\mathrm{u}}$,

where $X_{\mathrm{G}}^{\mathrm{d}}$ and $X_{\mathrm{G}}^{\mathrm{u}}$ stand for column-averaged DMFs at downwind and upwind sites.

Our sensors are two EM27/SUN FTS units owned by Harvard University and one owned by Los Alamos National Laboratory: nos. 45, 46, and 34 Bruker Optics (designated ha, hb, and $\mathrm{pl}$, respectively). They are compact $(62.5 \mathrm{~cm} \times 35.6 \mathrm{~cm} \times 47.3 \mathrm{~cm})$ and lightweight $(22.8 \mathrm{~kg}$ including the sun tracker), with a spectral resolution of $0.5 \mathrm{~cm}^{-1}$ and a scan time of $5.8 \mathrm{~s}$ (forward or backward scan). The EM27/SUN tracks the sun precisely ( $1 \sigma: 11$ arcsec) using a camera for fine alignment of the tracking mirrors (Gisi et al., 2011). It is mechanically very robust, with excellent precision in retrieving $X_{\mathrm{CO}_{2}}$ and $X_{\mathrm{CH}_{4}}$ (Gisi et al., 2012; Klappenbach et al., 2015; Hedelius et al., 2016), comparable to Bruker IFS 125HR used in the TCCON network (Wunch et al., 2011).

We carried out extensive side-by-side measurements of ha and hb in Cambridge, Massachusetts and Pasadena, California, over many months, thoroughly examining precision and robustness, and also compared these spectrometers to the TCCON spectrometer in Pasadena (Hedelius et al., 2016). We confirm that these spectrometers are stable (Frey et al., 2015). We show that comparing pairs of them cancels out most of the systematic error and bias from diverse sources, e.g., spectroscopic and retrieval errors, instrument bias, and errors in pressure and temperature, enabling us to determine $0.1 \%$ differences in column-averaged DMFs across the network.

\section{System characterization}

\subsection{Allan analysis for system precision}

Known standards cannot be exchanged for the ambient air in a total column measurement; hence it is difficult to assess the precision of atmospheric measurements end to end. Two commonly used literature methods for precision estimates are as follows.

- The first method is based on measurements of the standard deviation of the DMF time series, with the trend removed subtracting a moving average (Gisi et al., 2012). This approach is confounded by real variations in the atmosphere that occur on short timescales (vide infra).

- The second method is based on the residual of the spectral fit. The estimate obtained by this method does not separate systematic errors, e.g., errors in spectroscopic database and modeling of instrument line shape (ILS), from the measurement noise, and therefore this approach may overestimate the true random uncertainty of the measurement (cf. Fu et al., 2014).

In this paper we use the Allan variance method (Allan, 1966; Werle et al., 1993) to estimate the measurement precision. Figure 1 shows the Allan deviations of the differences in column-averaged DMFs measured simultaneously by ha and $\mathrm{hb}$ at the same location, i.e, $\Delta X_{\mathrm{G}}(t)=X_{\mathrm{G}}^{\mathrm{hb}}(t)-X_{\mathrm{G}}^{\mathrm{ha}}(t)$. The Allan variance of $\Delta X_{\mathrm{G}}$ is denoted by $\sigma_{\text {allan, } \Delta X_{\mathrm{G}}}^{2}$, which is the expectation value \langle\rangle of the difference between adjacent samples averaged over the time period $\tau$ :

$\sigma_{\text {allan, } \Delta X_{\mathrm{G}}}^{2}(\tau)=\frac{1}{2}\left\langle\left(\overline{\Delta X_{G, n+1}}-\overline{\Delta X_{G, n}}\right)^{2}\right\rangle$,

with

$\overline{\Delta X_{G, n}}=\frac{1}{\tau} \int_{t_{n}}^{t_{n}+\tau} \Delta X_{\mathrm{G}}(t) \mathrm{d} t$.

Practically, $\overline{\Delta X_{G, n}}$ is the mean of all $\Delta X_{\mathrm{G}}$ measurements within the time interval $\left[t_{n}, t_{n}+\tau\right)$.

According to the Allan deviation plots (Fig. 1), we made the following findings.

- The optimal integration time, given by the minimum in the Allan deviation, is 10 to $20 \mathrm{~min}$, for both $X_{\mathrm{CO}_{2}}$ and $X_{\mathrm{CH}_{4}}$.

- When averaging $10 \mathrm{~min}$, the precision (1 Allan deviation) of the EM27/SUN differential column measurement is $0.04-0.05 \mathrm{ppm}(0.01 \%)$ for $X_{\mathrm{CO}_{2}}$ and $0.1-$ $0.2 \mathrm{ppb}(0.01 \%)$ for $X_{\mathrm{CH}_{4}}$. Since the two instruments are statistically uncorrelated, the individual measurement noise is smaller by factor $1 / \sqrt{2}$, indicating precision comparable to near-infrared in situ laser spectrom- 

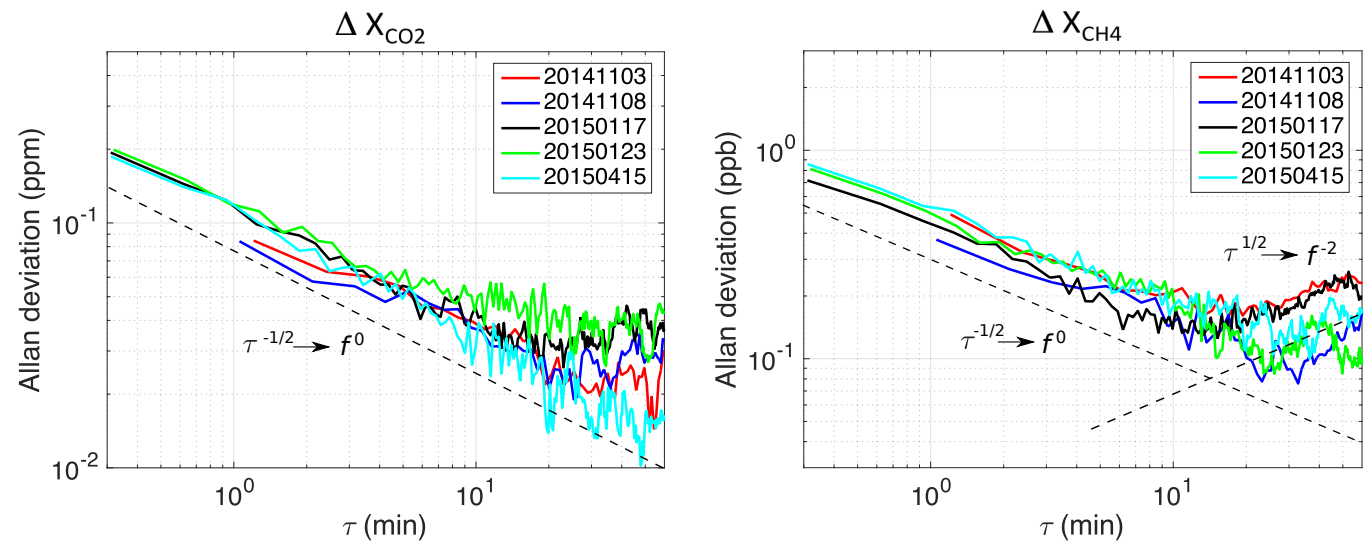

Figure 1. Allan deviations $\sigma_{\mathrm{allan}, \Delta X_{\mathrm{CO} 2}}$ and $\sigma_{\mathrm{allan}, \Delta X_{\mathrm{CH} 4}}$ as a function of the integrating time $\tau$. The black dashed lines represent a slope of $-1 / 2$ and a slope of $1 / 2$, which correspond to power spectral densities $S(f)=f^{0}$ (white noise) and $S(f)=f^{-2}$ (Brownian noise), respectively. The Allan deviation follows a slope of $-1 / 2$ up to an integration time of 10 to 20 min, then stays constant $\left(S(f)=f^{-1}\right)$, and subsequently turns over to a slope of $1 / 2$, which describes a drift.

eters with commensurate optical path length and integration time (Picarro, 2015a, b). Note that these precision estimates represent the full end-to-end processing of the observations, including deriving the spectrum from the interferogram, retrieving the column number densities in the atmosphere, and normalizing with the $\mathrm{O}_{2}$ column amount to obtain the column-averaged DMFs.

- When integrating less than $10 \mathrm{~min}$, the Allan deviation follows a slope of $-1 / 2$ in the double logarithmic scale, indicating white noise $\left(\tau^{-1 / 2} \rightarrow f^{0}\right)$ that has a constant power spectral density over the frequency $f$. As the averaging time $\tau$ increases beyond $10 \mathrm{~min}$, the Allan deviation rises a little, showing a small color noise component $\left(\tau^{1 / 2} \rightarrow f^{-2}\right)$, which arises from instrument drift, in part due to temperature differences inside of the spectrometers. There is also a small divergence between the measurements of ha and hb at high solar zenith angles, traceable to their slightly different ILSs. The measured ILS parameters are given in Appendix A. Microscale eddies have durations of $10 \mathrm{~s}$ to $10 \mathrm{~min}$ and length scales from tens to hundreds of meters (Stull, 1988, Fig. 2.2). Therefore atmospheric turbulence probably does not play a major role in the Allan plot because there is little color noise within timescale $\leq 10 \mathrm{~min}$ for two spectrometers looking along atmospheric paths separated by roughly one meter.

We use a shorter integration time $(5 \mathrm{~min})$ for measuring emissions from local- and regional-scale sources (Sects. 4.1 and 4.2), in order to retain high-frequency atmospheric signals, giving us precision of $0.05-0.06 \mathrm{ppm}$ for $\Delta X_{\mathrm{CO}_{2}}$ and $0.2-0.3 \mathrm{ppb}$ for $\Delta X_{\mathrm{CH}_{4}}$ (see Fig. 1). To study the short-term variations due to pollution plumes or turbulent eddies we use 2 min integration time (Sect. 4.3).

\subsection{System stability}

Differential column observations by two spectrometers will inevitably have bias in addition to fluctuations and drift. For the EM27/SUN, small differences in the alignments of the interferometers result in minute, but observable and systematic, deviations in the retrieval results. We examined the biases between ha and hb over a long period of time to determine whether these errors can be effectively corrected by applying a constant calibration factor to the retrieval of one instrument to match the performance of the other. The calibration factors are determined assuming a linear model, i.e., $X_{\mathrm{G}}^{\mathrm{hb}}=X_{\mathrm{G}}^{\mathrm{ha}} \cdot \overline{R_{\mathrm{G}}}$, and for each gas individually.

The value of $\overline{R_{\mathrm{G}}}$ was consistent over time for the two Harvard EM27/SUNs, including shipment across the contiguous United States (Fig. 2, Table 1). We used two retrieval software systems, I2S (interferogram-to-spectrum) combined with GFIT nonlinear least-squares spectral fitting retrieval software (Wunch et al., 2015; Hedelius et al., 2016), and PROFFIT (Hase et al., 2004). The calibration factors are slightly different for GFIT and PROFFIT, traceable to their specific modeling of the ILS, various a priori volume mixing ratio profiles, and unequal spectral microwindows that are used. Nevertheless, $\overline{R_{\mathrm{G}}}$ is consistent in Cambridge and Pasadena, before and during the campaign, when the same retrieval settings are used. Retrievals for ha have been scaled with $\overline{R_{\mathrm{G}}}$ for the Allan analysis (Sect. 3.1) and for the scientific applications (Sect. 4) below. Calibration factors for $\mathrm{pl}$ are shown in Appendix B. The measured ILS parameters of the two Harvard EM27/SUNs are also consistent over time and across continent, as given in Appendix A. 

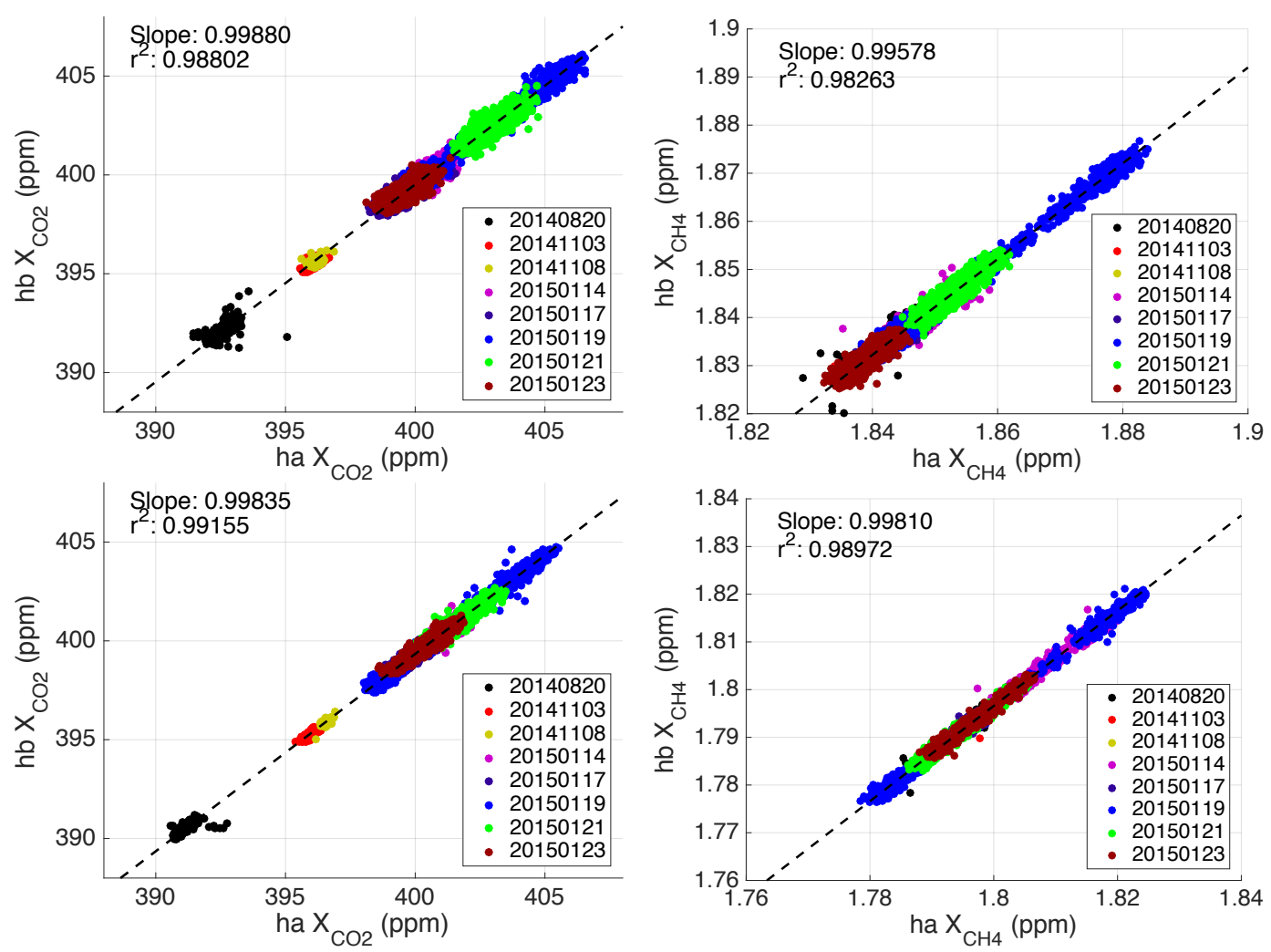

Figure 2. Scatter plots with the slopes representing $\overline{R_{\mathrm{G}}}$ for different days using I2S/GFIT retrieval (top panels) and PROFFIT retrieval (bottom panels). January measurements are carried out in Pasadena, others in Cambridge. The first 4 days are before the field study; others are during the campaign.

Table 1. Calibration factors $\overline{R_{\mathrm{G}}}$ for $X_{\mathrm{CH}_{4}}$ and $X_{\mathrm{CO}_{2}}$ before and during the field campaign, determined by forcing a linear regression line to go through the origin. $\overline{R_{\mathrm{G}}}$ for $X_{\mathrm{CH}_{4}}$ and $X_{\mathrm{CO}_{2}}$, determined using all data, are provided in the last row and used for the field study.

\begin{tabular}{llllll}
\hline & \multicolumn{2}{c}{$\overline{R_{\mathrm{CH}_{4}}}$} & & \multicolumn{2}{c}{$\overline{R_{\mathrm{CO}_{2}}}$} \\
\cline { 2 - 3 } \cline { 6 - 6 } & GFIT & PROFFIT & & GFIT & PROFFIT \\
\hline Before & 0.99574 & 0.99813 & & 0.99877 & 0.99838 \\
During & 0.99580 & 0.99809 & & 0.99881 & 0.99834 \\
Both & 0.99578 & 0.99810 & & 0.99880 & 0.99835 \\
\hline
\end{tabular}

\section{Scientific applications}

\subsection{Emission of an area source}

We measured the column-averaged dry-air mole fractions $X_{\mathrm{CO}_{2}}$ and $X_{\mathrm{CH}_{4}}$ simultaneously at locations upwind and downwind of the dairy farms in Chino, California, for several days in January 2015. Field results for ha, hb, and pl are shown in Fig. 4.

Meteorological conditions were particularly favorable on 24 January 2015, with consistent wind directions and wind speeds $\left(\sim 10 \mathrm{~m} \mathrm{~s}^{-1}\right)$ at both Chino airport $(\mathrm{KCNO} ; 1 \mathrm{~km}$ northeast of the downwind station ha) and Ontario airport (KONT; $3 \mathrm{~km}$ north of the upwind station hb) (Figs. 3a and 4a); 5 min averaged wind information from Automated Surface Observing System (ASOS) is used.

The measured methane enhancement $\Delta X_{\mathrm{CH}_{4}}$ was notably consistent at $\sim 2 \mathrm{ppb}$ over $5 \mathrm{~h}$ of measurement (Fig. $4 \mathrm{a}$, Table 2), 10 times larger than our measurement precision using 5 min integration time (see Sect. 3.1). Times between 0.1 and $0.7 \mathrm{~h}$ after solar noon were not taken into account because transient peaks were measured at the upwind site. The transient peaks are also observable at the downwind site but are weaker due to dispersion. More discussions on the transient peaks can be found in Sect. 4.3.2.

Winds were more variable on 15 January 2015 (Appendix F), with a consistent period of just $\sim 1 \mathrm{~h}$ at the two airports (Figs. $3 \mathrm{~b}$ and $4 \mathrm{~b}$ ), where the wind speeds were relatively light $\left(\sim 2 \mathrm{~m} \mathrm{~s}^{-1}\right)$. The observed $\Delta X_{\mathrm{CH}_{4}}$ was $\sim 10 \mathrm{ppb}$, a factor of 5 larger than on 24 January, showing inverse proportionality to the wind speed.

We use a simple column model (Jacob, 1999) and literature emission values to estimate $\Delta X_{\mathrm{G}}$ for the dairy farms 


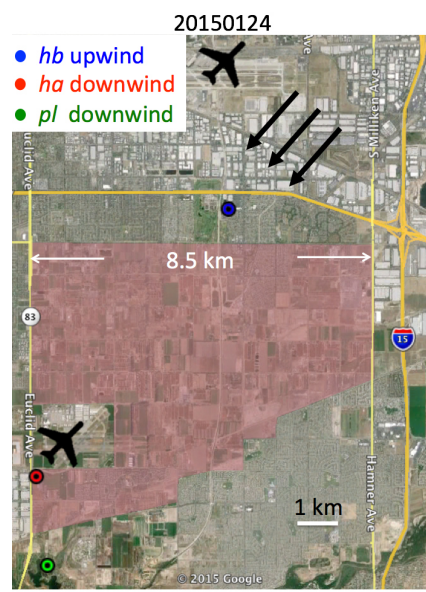

(a)

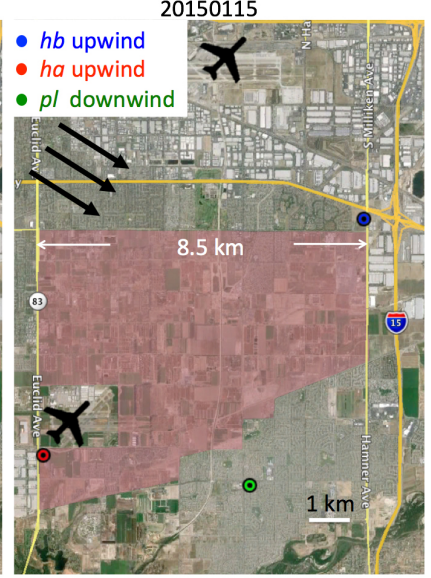

(b)

Figure 3. Locations of FTS stations and mean wind directions on 24 January 2015 (a) and 15 January 2015 (b). Map provided by Google Earth, Image Landsat, Data SIO, NOAA, US Navy, NGA, and GEBCO.

(area source) and to verify our measurements:

$\Delta X_{\mathrm{G}}=X_{\mathrm{G}}^{\mathrm{d}}-X_{\mathrm{G}}^{\mathrm{u}}=\frac{D}{\bar{U}} \times \frac{E_{\mathrm{G}}}{\text { column }_{\text {dryair }}}$,

where $E_{\mathrm{G}}$ is the mean emission flux (unit: molec. $\mathrm{m}^{-2} \mathrm{~s}^{-1}$ ) along the line traversing the area source, and $D$ is the length of the transect. column $n_{\text {dryair }}$ denotes the mean column number density of dry air. The frame of reference is the air column, which picks up the emissions of gas $G$ from the dairies as the air traverses the farms. The longer the air column travels in the emission field, the larger the difference between the column number densities of the downwind and upwind sites will become. $\Delta X_{\mathrm{G}}$ is therefore proportional to the residence time $D / \bar{U}$ of the air column and inversely proportional to the wind speed $\bar{U}$. This simple column model is applicable when the wind direction and speed are consistent across the area, and fluxes are uniform at plume scale.

Our model assumes that air parcels within the air column are transported with a mean velocity $\bar{U}$ in the horizontal direction, which can be estimated using real-time data for the wind speed at the surface. Using Reynolds' decomposition, the time series of horizontal $(u)$ and vertical $(w)$ wind speed are split into a mean part and a turbulent part, i.e.,

$$
\begin{aligned}
u(t) & =\bar{u}+u_{\mathrm{turb}}(t), & w(t) & =\bar{w}+w_{\mathrm{turb}}(t), \\
\sigma_{\mathrm{u}} & =\sqrt{<u_{\mathrm{turb}}^{2}>}, & \sigma_{\mathrm{w}} & =\sqrt{<w_{\mathrm{turb}}^{2}>.}
\end{aligned}
$$

$\sigma_{\mathrm{u}}$ and $\sigma_{\mathrm{w}}$ are the standard deviations of the turbulent components. We assume that the turbulence is horizontally homogeneous $\left(\sigma_{\mathrm{u}}\right.$ is independent of location) and isotropic $\left(\sigma_{\mathrm{w}}=\sigma_{\mathrm{u}}\right)$ and that the mean vertical wind speed $\bar{w}$ is zero. Strictly speaking, $\bar{U}$ denotes the "mass-enhancementweighted" wind velocity, i.e., $\bar{u}(z)$ weighted with the vertical

distribution of the $\mathrm{CH}_{4}$ molecules emitted from the dairies, denoted as $\mathrm{PDF}_{\Delta \mathrm{CH}_{4}}(z)$ :

$\bar{U}=\int_{0}^{\infty} \bar{u}(z) \operatorname{PDF}_{\Delta \mathrm{CH}_{4}}(z) \mathrm{d} z$.

Note if $\bar{u}(z)=$ const.; we have $\bar{U}=\bar{u}(z)=$ const., i.e., $\bar{U}$ is independent of the vertical distribution of the $\mathrm{CH}_{4}$ molecules being added in the column. However, since the wind speed generally increases with altitude, $\mathrm{PDF}_{\Delta \mathrm{CH}_{4}}(z)$ needs to be considered for the estimate of $\bar{U}$.

We assume $\Delta \mathrm{CH}_{4}$ is uniformly distributed up to a mixing height $z_{\mathrm{emiss}}$ and negligible above:

$$
\begin{aligned}
\operatorname{PDF}_{\Delta \mathrm{CH}_{4}}(z) & = \begin{cases}\frac{1}{z_{\text {emiss }}}, & 0 \leq z \leq z_{\mathrm{emiss}}, \\
0, & z>z_{\mathrm{emiss}},\end{cases} \\
\bar{U} & =\frac{1}{z_{\mathrm{emiss}}} \int_{0}^{z_{\text {emiss }}} \bar{u}(z) \mathrm{d} z .
\end{aligned}
$$

We use a 2-D random-walk model (McCrea and Whipple, 1940) to estimate $z_{\text {emiss }}$, the height to which $\mathrm{CH}_{4}$ emissions are transported vertically by turbulent flow. The number of the random-walk steps $n$ is given by the ratio between the average transit time of the emission $\tau_{\text {transit }}$ and the decorrelation time of the turbulent velocity fluctuations $\tau_{\text {eddy }}$, i.e.,

$n=\frac{\tau_{\text {transit }}}{\tau_{\text {eddy }}}=\frac{D \sigma_{\mathrm{w}}}{2 \bar{u} \lambda}$.

Assuming homogeneous emission, $\tau_{\text {transit }}$ is approximately $D / 2 \bar{u}$, with $\bar{u}$ representing the mean speed at the surface. This also corresponds to the transit time of a particle emitted at the center of the field. $\tau_{\text {eddy }}$ is given by $\lambda / \sigma_{\mathrm{w}}$, where $\lambda$ denotes the average eddy scale.

On 24 January, the mean horizontal wind speed over the entire measurement time is $11.35 \mathrm{~m} \mathrm{~s}^{-1}$ at KONT and $7.29 \mathrm{~m} \mathrm{~s}^{-1}$ at KCNO with a standard deviation $(1 \sigma)$ of $1.75 \mathrm{~m} \mathrm{~s}^{-1}$ and $1.59 \mathrm{~m} \mathrm{~s}^{-1}$, respectively. The wind directions are likewise very consistent over time, with a standard deviation of $8.9^{\circ}$ (KONT) and $6.5^{\circ}(\mathrm{KCNO})$. The wind speed at $10 \mathrm{~m}$ a.g.l. (above ground level) is assumed to be the average at the two airports over time, which gives $\bar{u}(10 \mathrm{~m})=9.3 \mathrm{~m} \mathrm{~s}^{-1}$ with fluctuations $\sigma_{\mathrm{u}}(10 \mathrm{~m})=$ $\sigma_{\mathrm{w}}(10 \mathrm{~m})=1.7 \mathrm{~m} \mathrm{~s}^{-1}$. Assuming an average eddy scale of $100 \mathrm{~m}$, the expected value of the height to which $\mathrm{CH}_{4}$ emissions rise is therefore

$z_{\text {emiss }}=\frac{\lambda \sqrt{n}}{\sqrt{2}}=\frac{1}{2} \sqrt{\frac{D \sigma_{\mathrm{w}}(10 \mathrm{~m}) \lambda}{\bar{u}(10 \mathrm{~m})}}=\frac{1}{2} \sqrt{D I \lambda} \approx 200 \mathrm{~m}$.

According to Taylor's hypothesis (Taylor, 1938), the turbulence intensity $I=\sigma_{\mathrm{u}} / \bar{u}$ should be constant, which indicates $z_{\text {emiss }}$ depends not on $\bar{u}$ but rather only on the eddy scale $\lambda$ and the turbulence intensity. 


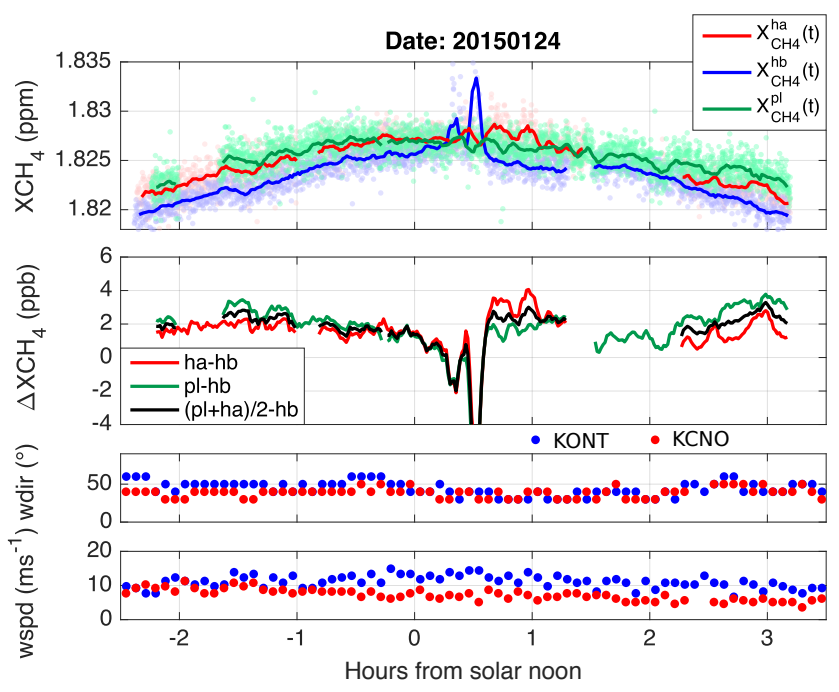

(a)
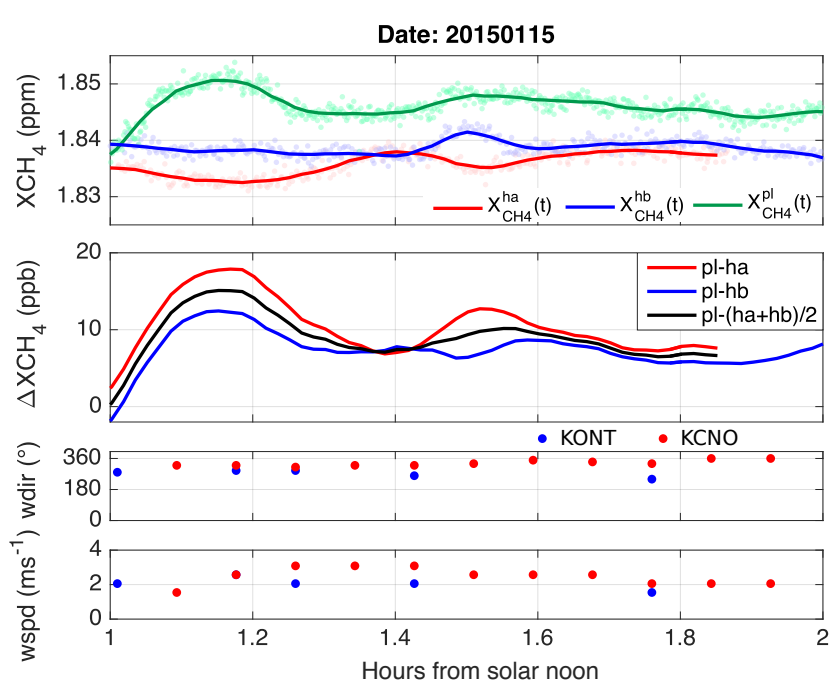

(b)

Figure 4. Column-averaged DMF measurements at three stations and downwind-minus-upwind column differences (solar zenith angle $\leq 70^{\circ}$ ). On 24 January, $\Delta X_{\mathrm{CH}_{4}}$ was steady at $\sim 2 \mathrm{ppb}$ most of the day, 10 times larger than our measurement precision (a). On 15 January, $\Delta X_{\mathrm{CH}_{4}}(t)$ was $\sim 10 \mathrm{ppb}$, about 5 times larger than on 24 January, showing inverse proportionality to the wind speed (b).

For determining $\bar{U}$ we need to consider the wind profile both in and above the surface layer. The wind follows a roughly logarithmic profile in the surface layer. At the middle portion of the PBL, the wind has typically constant direction and speed (Stull, 1988). Because the surface roughness information is not available, we use the power law to approximate the log wind profile in the surface layer and assume a constant horizontal wind speed above; i.e.,

$\bar{u}(z)= \begin{cases}\bar{u}(10 \mathrm{~m})\left(\frac{z}{10 \mathrm{~m}}\right)^{\alpha}, & 0 \leq z \leq z_{\mathrm{S}} \\ \bar{u}(10 \mathrm{~m})\left(\frac{z \mathrm{~S}}{10 \mathrm{~m}}\right)^{\alpha}, & z_{\mathrm{S}}<z<z_{\mathrm{PBL}}\end{cases}$

where $z_{\mathrm{S}}$ and $z_{\mathrm{PBL}}$ denote the depth of the surface layer and the PBL, respectively. The power law exponent $\alpha$ is approximately one-seventh for neutral stability conditions (Hsu et al., 1994).

Inserting Eq. (12) into Eq. (9), we obtain

$$
\begin{aligned}
\bar{U} & =\frac{\bar{u}(10 \mathrm{~m})}{z_{\text {emiss }}}\left(\int_{0}^{z_{\mathrm{S}}}\left(\frac{z}{10 \mathrm{~m}}\right)^{\alpha} \mathrm{d} z+\int_{z_{\mathrm{S}}}^{z_{\text {emiss }}}\left(\frac{z_{\mathrm{S}}}{10 \mathrm{~m}}\right)^{\alpha} \mathrm{d} z\right) \\
& =\bar{u}(10 \mathrm{~m})\left(\frac{z_{\mathrm{S}}}{10 \mathrm{~m}}\right)^{\alpha}\left(1-\frac{z_{\mathrm{S}}}{z_{\text {emiss }}} \frac{\alpha}{\alpha+1}\right) .
\end{aligned}
$$

Varying $z_{\mathrm{s}}$ in the range of $10 \mathrm{~m}$ to $z_{\text {emiss }}$, we obtain $\bar{U}$ in the range of 9.3 to $12.5 \mathrm{~m} \mathrm{~s}^{-1}$, corresponding to an average of $10.9 \mathrm{~m} \mathrm{~s}^{-1} \pm 15 \%$. The lower bound is given by a constant wind speed starting from $10 \mathrm{~m}$ a.g.l., and the upper bound assumes a wind profile power law up to the mixing height $z_{\text {emiss }}$ of $200 \mathrm{~m}$.

Our wind model is consistent with the wind profiles taken during aircraft taking off and landing at Ontario air- port via Aircraft Communications Addressing and Reporting System (ACARS) and also agrees well with the Hybrid Single-Particle Lagrangian Integrated Trajectory (HYSPLIT) model simulations (Stein et al., 2015; Draxler and Hess, 1998), driven by the meteorological model North American Mesoscale Forecast System (NAM) with a horizontal resolution of $12 \mathrm{~km}$. The comparisons can be found in Appendix E.

Oxygen column number density is determined as $4.493 \times$ $10^{28}$ molec. $\mathrm{m}^{-2} \pm 0.5 \%$ (Appendix D), accounting for $20.95 \%$ of dry air. According to Eq. (4), the uncertainty in calculating $E_{\mathrm{G}}$ from $\Delta X_{\mathrm{G}}$ is the sum of the uncertainties in $\bar{U}(15 \%), \Delta X_{\mathrm{G}}(0.01 \%$ precision $)$, and column dryair $(0.5 \%)$, in total roughly $16 \%$. Therefore, an emission estimate using differential column measurements is dominated by the uncertainty in the transport (i.e., $\bar{U}$ ), not the differential column measurements themselves.

Since the two spectrometers have identical optical setup, spectral resolution, and measuring geometry, their column averaging kernels are very similar and happen to be close to one at all altitudes (Hedelius et al., 2016). The uncertainty arising from the differences in averaging kernels is included in the uncertainty in $\Delta X_{\mathrm{G}}$. The sensitivity of the retrieved $X_{\mathrm{CH}_{4}}$ on surface pressure inputs is discussed in Appendix C.

In Table 2, the time-averaged $\Delta X_{\mathrm{CH}_{4}}$ and their corresponding emission numbers are listed. Measurements between 0.1 and $0.7 \mathrm{~h}$ after solar noon are neglected due to the transient peaks measured with hb (Fig. 4a).

We can compare our measurements to the value of $\Delta X_{\mathrm{CH}_{4}}$ derived from literature annual mass emission rates $E_{\mathrm{CH}_{4} \text {,annual }}$ for the dairy farms. Peischl et al. (2013) determined $28 \mathrm{Gg} \mathrm{yr}^{-1}$ using a bottom-up method accounting 
Table 2. Time-averaged $\Delta X_{\mathrm{CH}_{4}}$, using ha or pl, or ha and $\mathrm{pl}$ as downwind stations on 24 January 2015, and their corresponding emission numbers calculated using Eq. (4). $\Delta X_{\mathrm{CH}_{4}}$ is rounded to one decimal place in the table, whereas for the calculation of $E_{\mathrm{CH}_{4}}$ and $E_{\mathrm{CH}_{4} \text {, annual }}$ all available digits are used. The uncertainty of $16 \%$ is given by the uncertainties in $\bar{U}$, column dryair, and $\Delta X_{\mathrm{G}}$. Uncertainty in $E_{\mathrm{CH}_{4}}$, annual is $16 \%$ added with $10 \%$ uncertainty in the emission area. This table also displays the annual emission rates estimated by Peischl et al. (2013) using bottom-up and top-down methods. The corresponding column differences $\Delta X_{\mathrm{CH}_{4}}$ and their uncertainties, as derived in Eq. 14, are summarized in the second column.

\begin{tabular}{|c|c|c|c|}
\hline Configuration & $\begin{array}{r}\Delta X_{\mathrm{CH}_{4}} \\
(\mathrm{ppb})\end{array}$ & $\begin{array}{r}{ }_{\mathrm{CH}_{4}} \\
\left(\text { molec. } \mathrm{m}^{-2} \mathrm{~s}^{-1} \text { ) }\right.\end{array}$ & $\begin{array}{r}E_{\mathrm{CH}_{4} \text {,annual }} \\
\left(\mathrm{Gg} \mathrm{yr}^{-1}\right)\end{array}$ \\
\hline$h a-h b$ & 1.8 & $5.38 \times 10^{17}( \pm 16 \%)$ & $22.5( \pm 26 \%)$ \\
\hline $\mathrm{pl}-\mathrm{hb}$ & 2.1 & $6.15 \times 10^{17}( \pm 16 \%)$ & $25.8( \pm 26 \%)$ \\
\hline$(\mathrm{pl}+\mathrm{ha}) / 2-\mathrm{hb}$ & 2.1 & $6.09 \times 10^{17}( \pm 16 \%)$ & $25.5( \pm 26 \%)$ \\
\hline Peischl's bottom-up & $2.3( \pm 0.6)$ & & 28.0 \\
\hline Peischl's top-down & $(4.0 \pm 1.0)( \pm 50 \%)$ & & $49.0( \pm 50 \%)$ \\
\hline
\end{tabular}

for enteric fermentation and dry manure management and $49( \pm 50 \%) \mathrm{Gg} \mathrm{yr}^{-1}$ using a top-down method with aircraftbased mass balance approach during the CalNex field study. We assume a dairy area (area $\mathrm{emiss}_{\text {) }}$ of $50 \mathrm{~km}^{2} \pm 10 \%$ and a constant emission rate across the farm throughout day and

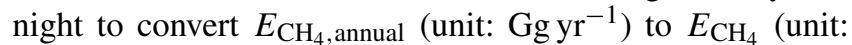
molec. $\mathrm{m}^{-2} \mathrm{~s}^{-1}$ ). The transect length $D$ is approximated with $8 \mathrm{~km}$, which is the diameter of a circle with $50 \mathrm{~km}^{2}$ area.

For 24 January 2015,

$$
\begin{aligned}
& \Delta X_{\mathrm{CH}_{4}, \text { expected }} \\
& =\frac{D}{\bar{U}} \times \frac{E_{\mathrm{CH}_{4}, \text { annual }}(\text { Peischl's number })}{m_{\mathrm{CH}_{4}} \cdot \text { area }_{\mathrm{emiss}} \cdot N_{\mathrm{s} \mathrm{year}^{-1}} \cdot \text { column }_{\mathrm{dryair}}} \\
& = \begin{cases}2.3 \pm 0.6 \mathrm{ppb}, & \text { for } 28 \mathrm{Gg} \mathrm{yr}^{-1}(\text { bottom-up }) \\
(4.0 \pm 1.0)( \pm 50 \%) \mathrm{ppb}, & \text { for } 49( \pm 50 \%) \mathrm{Gg} \mathrm{yr}^{-1} \text { (top-down) }\end{cases}
\end{aligned}
$$

where $m_{\mathrm{CH}_{4}}$ denotes the molecular mass of methane (unit: g molec. ${ }^{-1}$ ) and $N_{\text {s year }^{-1}}$ represents the number of seconds per year.

The observed $\Delta X_{\mathrm{CH}_{4}}, \sim 2 \mathrm{ppb}$ (Fig. 4a, Table 2), falls in the lower half of the range from Peischl. Our results and Peischl's top-down estimates both represent just a few days of data. The difference with Peischl's results using the aircraftbased mass balance approach could be due to seasonal factors, activity levels at the farms, uncertainties in $\bar{U}$ as well as in background concentrations and in boundary layer depth for the aircraft measurements (Cambaliza et al., 2014), or model errors. Longer deployments with more ancillary data, such as wind profiles, would be needed to refine the result. Further studies using a Weather Research and Forecasting (WRF) model in large-eddy simulation (LES) mode will be presented in Viatte et al. (2016). The differential column measurement using compact FTSs has shown the capability to determine the emission flux when deployed across an area source such as Chino farms.

\subsection{Source characterization using ratios of column differences}

Pasadena is a city within the South Coast Air Basin (SCAB) with heterogeneous $\mathrm{CO}_{2}$ and $\mathrm{CH}_{4}$ emissions, from different source types such as transportation, electricity generation, industry, landfills, and gas leaks in the natural gas delivery system. The ratio of column differences can be used to characterize regional emissions. For example, Wunch et al. (2009) measured diurnal changes of $X_{\mathrm{CH}_{4}}, X_{\mathrm{CO}_{2}}$, and $X_{\mathrm{CO}}$ (temporal difference) and used the $\mathrm{CO}_{2}$ emission inventories from the California Air Resources Board (CARB) and EDGAR (Emission Database for Global Atmospheric Research) to estimate emissions of $\mathrm{CH}_{4}$ and $\mathrm{CO}$ in the $\mathrm{SCAB}$.

We deployed two EM27/SUN spectrometers, ha and hb, located north $\left(34.20^{\circ} \mathrm{N}, 118.13^{\circ} \mathrm{W} ; 552 \mathrm{~m}\right.$ a.s.l. $)$ and south $\left(34.11^{\circ} \mathrm{N}, 118.14^{\circ} \mathrm{W} ; 170 \mathrm{~m}\right.$ a.s.l.) of Pasadena, on $27 \mathrm{Jan}-$ uary 2015, as shown in Fig. 6, left panel. We measured the column difference between ha and hb during the course of a day, i.e., $\Delta X_{\mathrm{G}}(t)=X_{\mathrm{G}}^{\mathrm{hb}}(t)-X_{\mathrm{G}}^{\mathrm{ha}}(t)$, which is shown in Fig. 5 (third panel).

We determine the ratio of spatial column differences $\Delta X_{\mathrm{CH}_{4}} / \Delta X_{\mathrm{CO}_{2}}$ across Pasadena by linear regression of $\Delta X_{\mathrm{CH}_{4}}$ and $\Delta X_{\mathrm{CO}_{2}}$ data, using maximum likelihood estimation (York et al., 2004, see Fig. 6). The derived ratio over the course of the day $\left(7.8 \pm 0.1 \mathrm{ppb} \mathrm{ppm}^{-1}\right)$ is consistent with the emission ratios determined by comparing the daily variations of $X_{\mathrm{CH}_{4}}$ and $X_{\mathrm{CO}_{2}}\left(7.8 \pm 0.8 \mathrm{ppb} \mathrm{ppm}^{-1}\right)$ reported at a TCCON station (Wunch et al., 2009) located at JPL $\left(34.2^{\circ} \mathrm{N}, 118.2^{\circ} \mathrm{W} ; 390 \mathrm{~m}\right.$ a.s.l.) and likewise for the ratio of enhancements obtained by the California Laboratory for Atmospheric Remote Sensing FTS (7.28 $\pm 0.09 \mathrm{ppb} \mathrm{ppm}^{-1}$; Wong et al., 2015), which compared DMFs from diffuse solar reflectance off a Spectralon plate at Mount Wilson $\left(34.22^{\circ} \mathrm{N}\right.$, $118.06^{\circ} \mathrm{W} ; 1670 \mathrm{~m}$ a.s.l.) with those from reflected sunlight from West Pasadena $\left(34.17^{\circ} \mathrm{N}, 118.17^{\circ} \mathrm{W}\right)$.

By coloring the ratios of column differences per hour (Fig. 7), we observe a difference in the ratios be- 


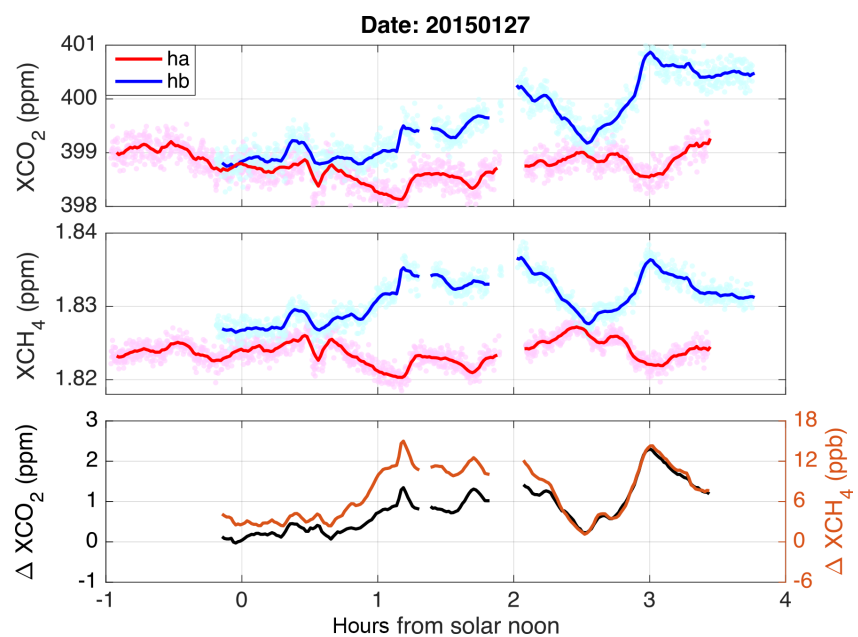

Figure 5. First and second panels: measured $X_{\mathrm{CO}_{2}}$ and $X_{\mathrm{CH}_{4}}$ north (ha) and south (hb) of Pasadena on 27 January with 5 min averaging time. Third panel: $\Delta X_{\mathrm{CO}_{2}}$ and $\Delta X_{\mathrm{CH}_{4}}$ are temporally correlated and their ratio is determined as $7.8 \mathrm{ppb} \mathrm{ppm}^{-1}$, shown in Fig. 6.
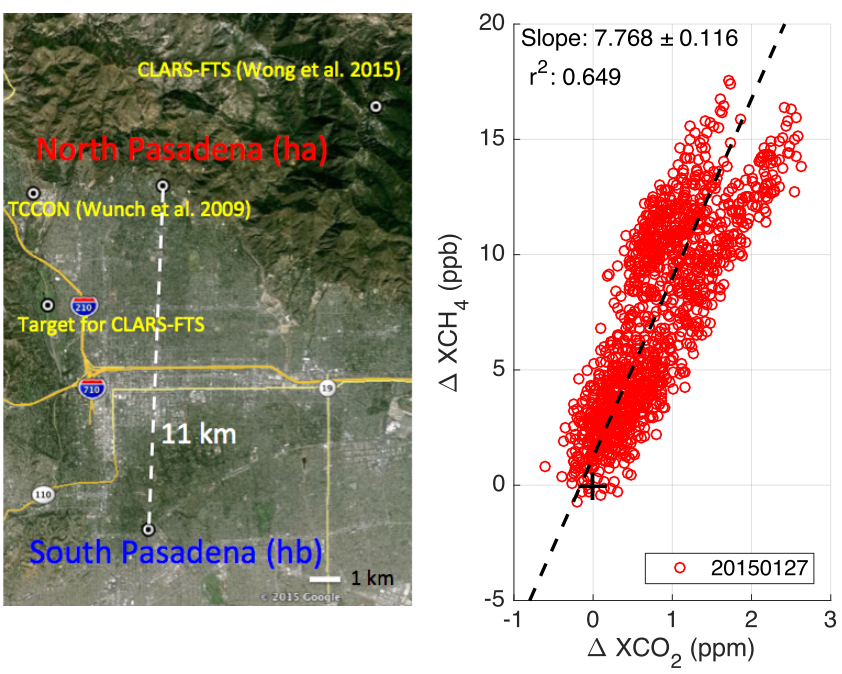

Figure 6. The derived ratio of column differences across Pasadena is consistent with Wunch et al. (2009) using TCCON DMF daily dynamics and very close to the excess ratio determined in Wong et al. (2015), which compared DMFs from diffuse solar reflectance off a Spectralon plate at Mount Wilson with those from reflected sunlight from West Pasadena. Map provided by Google Earth, Image Landsat, Data SIO, NOAA, US Navy, NGA, and GEBCO.

tween noon $\left(9.96 \pm 0.22 \mathrm{ppb} \mathrm{ppm}^{-1}\right)$ and afternoon time $\left(6.65 \pm 0.15 \mathrm{ppb} \mathrm{ppm}^{-1}\right)$, with both regression curves passing essentially through the origins. We determined a higher $\Delta X_{\mathrm{CO}_{2}} / \Delta X_{\mathrm{CH}_{4}}$ ratio in the afternoon than the noon time, which can be caused by more traffic emissions in the basin. The lagged cross covariance between $\Delta X_{\mathrm{CO}_{2}}$ and $\Delta X_{\mathrm{CH}_{4}}$ peaks at zero lag (Appendix G, Fig. G1, third panel), and the peak value is interestingly higher than the peak values of the cross covariance functions between $X_{\mathrm{CO}_{2}}$ and $X_{\mathrm{CH}_{4}}$
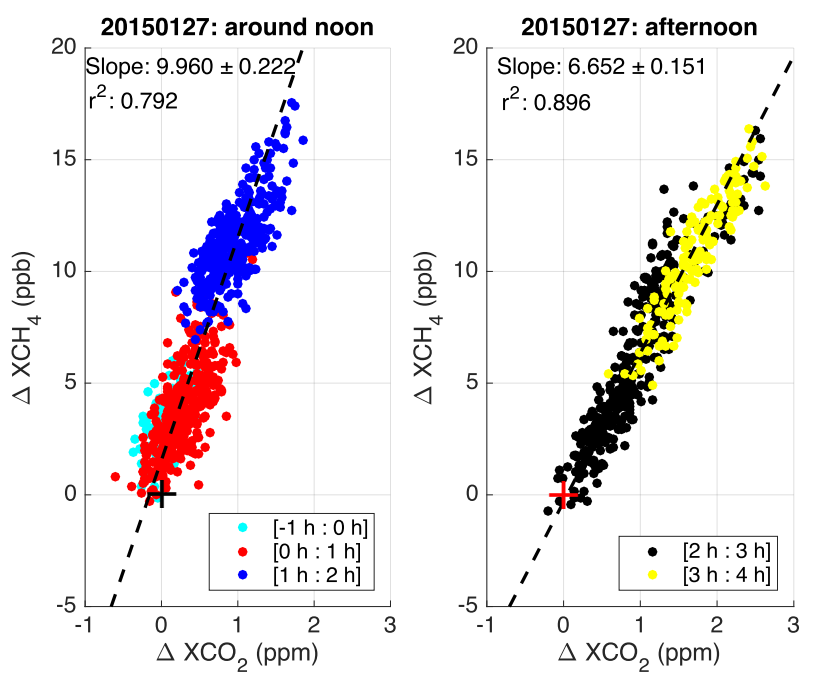

Figure 7. Column difference ratios measured across Pasadena colored by hours. Left figure shows the time period between $1 \mathrm{~h}$ before solar noon and $2 \mathrm{~h}$ after solar noon, and right figure shows the time period 2 to $4 \mathrm{~h}$ after solar soon. The solar noon is about 12:05 local time. Both regression curves essentially pass through the origins that are shown as crosses.

at individual sites (Fig. G1, first and second panels), which suggests the column difference is sensitive to the emissions between the two sites.

The Pasadena study confirms that sources of $\mathrm{CH}_{4}$ are surprisingly large from $\mathrm{SCAB}$, as reported by previous papers using aircraft and TCCON data (Wunch et al., 2009; Wennberg et al., 2012; Peischl et al., 2013). The capability of determining emission ratios using ratios of spatial column differences has been illustrated in this section.

\subsection{Short-term variations}

\subsubsection{Side-by-side measurements}

We observed short-term variations in side-by-side measurements at Caltech and Harvard. These fluctuations are captured by both instruments simultaneously, representing geophysical phenomena, not noise as might be assumed. The high-frequency temporal structure $(\sim 5-10 \mathrm{~min}$ full width at half maximum) can be caused by emissions not well mixed within the boundary layer ("plumes"), by turbulence across the top of the ML, or by intrusions of a sea breeze front that introduces a different volume of air to the column.

In Fig. 8 we show, as an example, side-by-side measurements at Caltech. Short-term variations in $X_{\mathrm{CO}_{2}}$ as large as $1 \mathrm{ppm}$ are observed between 19:30 and 23:00 UTC. These features are only present in $X_{\mathrm{CO}_{2}}$, not in $X_{\mathrm{CH}_{4}}$. The wind directions during that time period were variable between southsouthwest and northwest, indicating the short-term variations are likely due to excess $\mathrm{CO}_{2}$ emissions from a $12.5 \mathrm{MW}$ combined heat and power plant located $\sim 200 \mathrm{~m}$ to the south- 

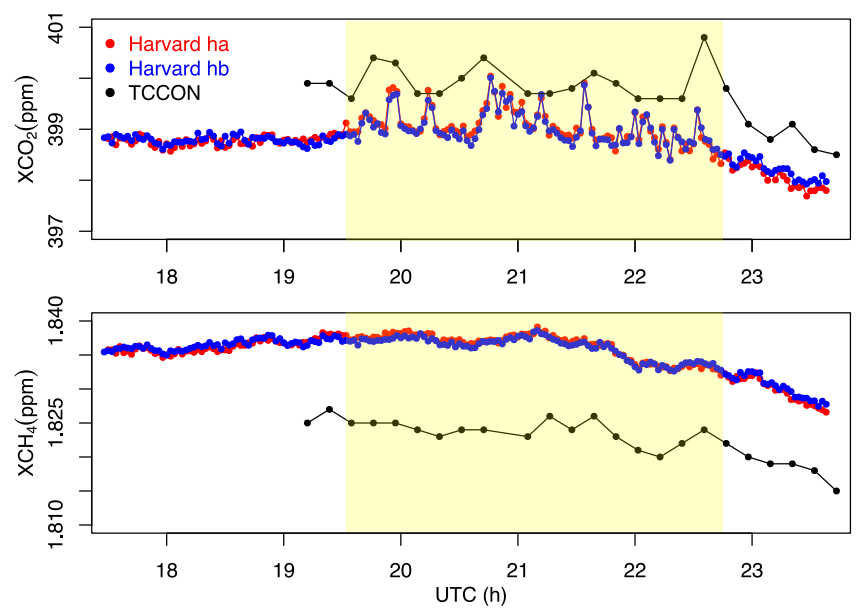

Figure 8. Side-by-side measurements on the roof of the Linde+Robinson Laboratory on Caltech campus (17 January 2015, 2 min block average). Both EM27/SUN spectrometers captured short-term variations in the $X_{\mathrm{CO}_{2}}$ signal $(\sim 1 \mathrm{ppm}$ corresponds to $0.25 \%$ relative). The TCCON spectrometer does not resolve these short-term variations due to the low measurement rate.

southwest and/or a solid oxide fuel cell $\sim 20 \mathrm{~m}$ to the northwest. Note that, because the co-located TCCON spectrometer samples at a lower rate, these variations are not well resolved in the TCCON data (Wennberg et al., 2014).

Figure 9 shows another example in Greater Boston where $X_{\mathrm{CO}_{2}}$ and $X_{\mathrm{CH}_{4}}$ vary together by approximately the same relative amount $(0.1-0.2 \%)$ at 12:00-13:00 UTC, also correlated with changes $(\sim 10 \%)$ in the mean normalized relative backscatter (NRB) measured from our lidar station $3 \mathrm{~km}$ away (Appendix H). The wind measurements at Boston Logan International Airport (KBOS), showing easterly winds during that time period, differ from New Bedford Regional Airport (KBED), indicating a sea breeze event that likely generates wind shear and turbulence across the top of the ML. The depth of PBL undergoes short-term variations that are also visible in the lidar data at 12:30 UTC. In this case, the column-averaged DMFs vary because the proportion of PBL air in the whole column changes. Also the sea breeze circulation pushes a different volume of air through the column, which could result in a sporadic jump of $X_{\mathrm{CO}_{2}}$ and $X_{\mathrm{CH}_{4}}$. The short-term variation of $X_{\mathrm{CO}_{2}}$ at 14:30-15:30 UTC is not observed in $X_{\mathrm{CH}_{4}}$ and the lidar data. It is probably caused by $\mathrm{CO}_{2}$ plumes within the PBL, similar to what we observed at Caltech and shown in Fig. 8.

\subsubsection{Transient peak at Chino}

Not only for side-by-side measurements but also during the field measurement are short-term peaks observed, as mentioned in Sect. 4.1. Transient peaks are moving from the upwind to the downwind site: they are observable at upwind site
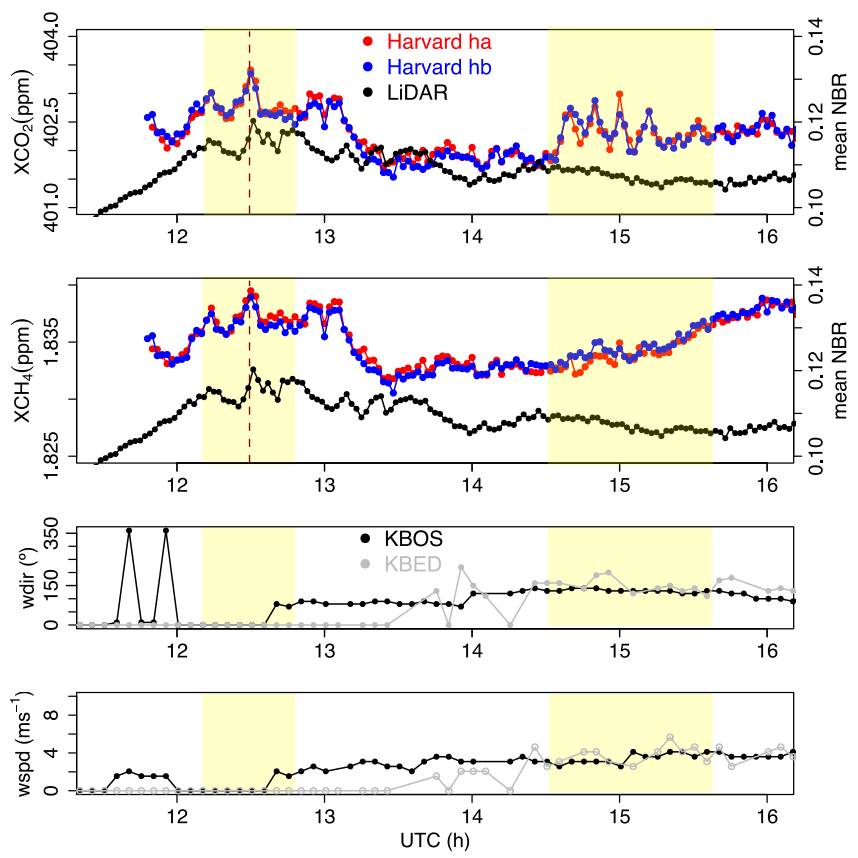

Figure 9. Short-term variations in $X_{\mathrm{CO}_{2}}$ and $X_{\mathrm{CH}_{4}}$ observed on the roof of Harvard Science Center by ha and hb (16 April 2015, 2 min block average). A lidar metric of the thickness of the PBL (mean NRB 0-1.5 km a.g.l.) from a nearby site (Boston University, $3 \mathrm{~km}$ to the south-southeast of our site) is overlaid on top. The NRB signal is positively correlated with the short-term variations of the FTS measurements at 12:00-13:00 UTC.

$\mathrm{hb}$ between 0.1 and $0.7 \mathrm{~h}$ after solar noon and at ha between 0.5 and $1.1 \mathrm{~h}$ after solar noon (Fig. 10). They are not observable at $\mathrm{pl}$ site, probably because the plume is very narrow. Compared to the upwind peaks, the downwind peaks have a time shift and are weaker and broader due to air dispersion. The peaks traveling from upwind to downwind site along the trajectory provide a proof that the same air mass is sampled.

The transient peaks are not observed in $X_{\mathrm{CO}_{2}}$, indicating they are not caused by passing clouds or from a power plant. They may come from natural gas leaks from the pipelines in the Chino area, with some evidence being reported by environmental defense fund (EDF, 2016). The transient peaks are removed from the column difference study (Sect. 4.1), because they are not associated with the local dairy farms.

The short-term variation helps us to understand the limitation of sampling using column measurements, which is relevant to the gradient determination and to satellite data. It is highly desirable to avoid aliasing these variations and to characterize, model, and/or measure the influences that cause these variations. 

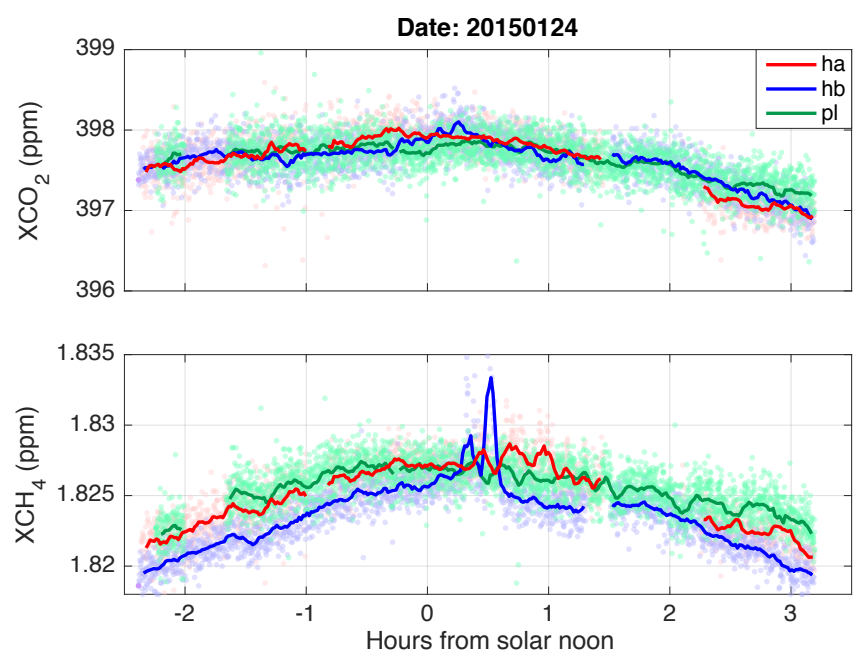

Figure 10. Observed $X_{\mathrm{CO}_{2}}$ (upper panel) and $X_{\mathrm{CH}_{4}}$ (bottom panel) at ha, hb, and pl sites on 24 January 2015; the transient peaks in $X_{\mathrm{CH}_{4}}$ are not observed for $X_{\mathrm{CO}_{2}}$.

\section{Conclusions}

In this paper we demonstrated how to design observations of, and interpret, spatial gradients of column-averaged dryair mole fractions for trace gases $\left(\mathrm{CO}_{2}, \mathrm{CH}_{4}\right)$. We showed that the differential column methodology can be applied to the urban source problem and to other regional source-sink determinations.

We made extensive side-by-side measurements using two EM27/SUNs, in Cambridge and Pasadena, over many months. The differential system has a precision of $0.01 \%$ for both $X_{\mathrm{CO}_{2}}$ and $X_{\mathrm{CH}_{4}}$ according to the Allan variance analysis when using an optimum integrating time of $10 \mathrm{~min}$. The system is very stable in measuring column concentrations over time and after relocation across the continent.
We tested the gradient measurement and its sensitivity to emission sources by measuring the downwind-minusupwind column differences $\Delta X_{\mathrm{CH}_{4}}$ across dairy farms in the Chino area. The column difference measurements are at least 10 times larger than the measurement precision, and are inversely proportional to the wind speed. The derived emission numbers using a column model were consistent with the bottom-up source strength given by Peischl et al. (2013) and lie on the lower end of their top-down estimates using aircraft-based mass balance approach. Ratios of spatial column differences $\Delta X_{\mathrm{CH}_{4}} / \Delta X_{\mathrm{CO}_{2}}$ were measured across Pasadena within the SCAB, with values consistent with emission ratios from the literature.

We observed significant short-term variations of $X_{\mathrm{CH}_{4}}$ and $X_{\mathrm{CO}_{2}}$, and we showed that they are not noise or variations of optical path length but rather represent atmospheric phenomena. These measurements provide useful information for measuring pollution plumes, turbulence across the top of the mixed layer, and transient peaks.

Overall, this paper helps establish a range of new applications for compact solar-tracking Fourier transform spectrometers and shows the capability of differential column measurements for determining urban emissions. By accurately measuring the differences in the integrated column amounts across local and regional sources, we directly observe the mass loading of the atmosphere due to the influence of emissions in the intervening locale. The inference of the source strength is much more direct than inversion modeling using only surface concentrations and less subject to errors associated with small-scale transport phenomena. The advent of compact, robust solar-viewing spectrometers opens up myriad applications not hitherto pursued.

\section{Data availability}

The data for this study are available at http://dx.doi.org/10. 7910/DVN/J2YPX3 (Chen et al., 2016). 


\section{Appendix A: Instrument line shape function parameters}

The measured spectrum is a convolution between the atmospheric spectrum and instrument line shape in the frequency domain ILS $(v)$. In the ideal case, ILS $(v)$ is a delta function, which corresponds to a constant modulation efficiency for all optical path differences (OPDs). However, in practice, $\operatorname{ILS}(v)$ is broader than a delta impulse, caused by the spectrometer's finite OPD, finite aperture size, and also misalignment of the interferometer. The ILS in the interferogram domain can be approximated using a simple model that assumes a linear decay of the modulation efficiency with increasing OPD and a constant phase error (Hase et al., 1999).

We estimated the ILS parameters of both spectrometers with an experimental setup, similar to that described in Frey et al. (2015), and determined the modulation efficiency at maximum OPD $\left(\mathrm{OPD}_{\max }\right)$ and phase error using the simple model implemented in the LINEFIT software (Hase et al., 1999). Matlab scripts for automation purposes have been developed and can be obtained from the corresponding author.

Even though the measured ILS parameters are different for the two spectrometers due to the different internal alignment, the ILS of each single instrument is consistent over time and after relocation of the instrument across the contiguous USA (see Table A1).

Table A1. Modulation efficiency and phase error determined for EM27/SUN ha and hb in Cambridge and Pasadena.

\begin{tabular}{lcc}
\hline Cambridge & & \\
\hline Instrument & $\begin{array}{c}\text { Modulation efficiency } \\
\text { at OPD }\end{array}$ & $\begin{array}{c}\text { Phase error } \\
(\mathrm{rad})\end{array}$ \\
\hline $\mathrm{ha}$ & 0.975 & $-3 \times 10^{-3}$ \\
$\mathrm{hb}$ & 0.988 & $5 \times 10^{-3}$ \\
\hline Pasadena & \multicolumn{3}{c}{} \\
\hline Instrument & $\begin{array}{c}\text { Modulation efficiency } \\
\text { at OPD }\end{array}$ & $\begin{array}{c}\text { Phase error } \\
(\mathrm{rad})\end{array}$ \\
\hline ha & 0.973 & $-2 \times 10^{-3}$ \\
hb & 0.991 & $4 \times 10^{-3}$ \\
\hline
\end{tabular}

\section{Appendix B: Calibration factors for ha and pl}

Table B1. Calibration factors for ha and pl to match hb, for $X_{\mathrm{CH}_{4}}$, $X_{\mathrm{CO}_{2}}$, and oxygen column number density measurements, determined using GFIT retrieval.

\begin{tabular}{lrrr}
\hline Instrument & $\overline{R_{\mathrm{CH}_{4}}}$ & $\overline{R_{\mathrm{CO}_{2}}}$ & $\overline{R_{\mathrm{O}_{2}}}$ \\
\hline ha & 0.99578 & 0.99880 & 1.00846 \\
pl & 1.00093 & 0.99930 & 0.99712
\end{tabular}

Table B1 shows the calibration factors for ha and $\mathrm{pl}$ to match hb measurements, determined by linear regressions of the side-by-side measurements at Harvard and Caltech.

The linear models applied are

$$
\begin{array}{ll}
X_{\mathrm{CH}_{4}}^{\mathrm{hb}}=X_{\mathrm{CH}_{4}}^{\mathrm{ha}} \cdot \overline{R_{\mathrm{CH}_{4}}^{\mathrm{ha}}}, \quad X_{\mathrm{CH}_{4}}^{\mathrm{hb}}=X_{\mathrm{CH}_{4}}^{\mathrm{pl}} \cdot \overline{R_{\mathrm{CH}_{4}}^{\mathrm{pl}}}, \\
X_{\mathrm{CO}_{2}}^{\mathrm{hb}}=X_{\mathrm{CO}_{2}}^{\mathrm{ha}} \cdot \overline{R_{\mathrm{CO}_{2}}^{\mathrm{ha}}}, \quad X_{\mathrm{CO}_{2}}^{\mathrm{hb}}=X_{\mathrm{CO}_{2}}^{\mathrm{pl}} \cdot \overline{R_{\mathrm{CO}_{2}}^{\mathrm{pl}}}, \\
\text { column }
\end{array}
$$



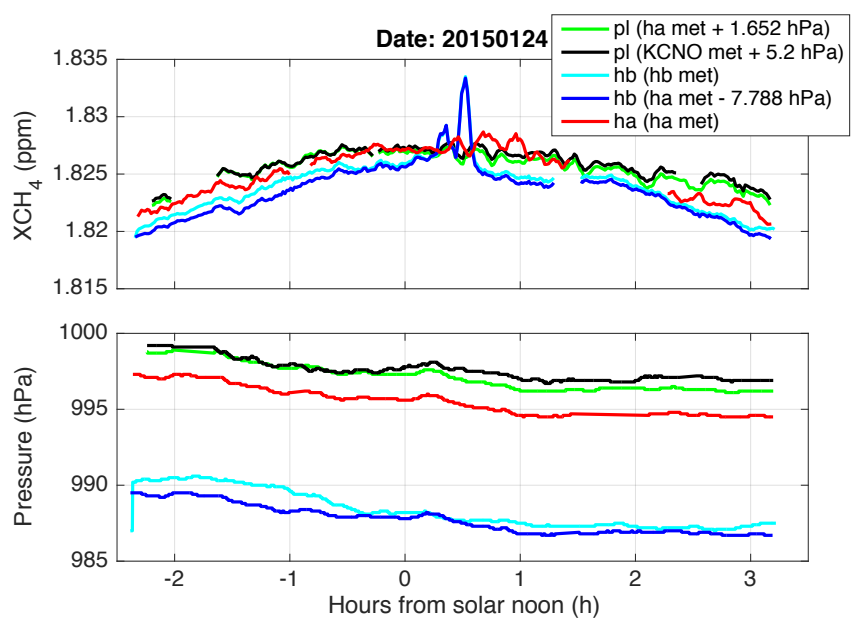

Figure C1. Surface pressure inputs (lower panel) and the corresponding $\mathrm{X}_{\mathrm{CH}_{4}}$ retrieval results using $5 \mathrm{~min}$ moving average (upper panel). For Fig. 4a and the simple column model calculations, ha, $\mathrm{hb}$, and pl retrievals with the surface pressure inputs based on ha onsite pressure measurements are used (red, blue, and green curves).

\section{Appendix C: Retrieval sensitivity to pressure inputs}

Surface pressure $p_{\text {surf }}$ is a main input for the GFIT retrieval to derive the site pressure altitude for each spectrum (Wunch et al., 2011). Inaccurate pressure measurements will introduce errors in the computed widths of the gas absorption lines, i.e., pressure broadening, and therefore the fitted volume mixing ratio scale factors (Wunch et al., 2011) will be inadequate, with a biased column-averaged DMF as a result.

On 24 January, the surface pressure measurement at pl site failed, and therefore we assess $p_{\text {surf }}^{\mathrm{pl}}$ using pressure measurements at the closest FTS station ha and the nearby airport $\mathrm{KCNO}$. We assume hydrostatic equilibrium and a $1.18 \mathrm{hPa}$ pressure difference per $10 \mathrm{~m}$ altitude difference. We derived $\Delta p_{\text {surf }}$ using the altitude difference between $\mathrm{pl}$ and ha, as well as pl and KCNO airport, and these two methods provide very similar results (Fig. C1). For the simple column model calculations, the retrieval with $p_{\text {surf }}^{\mathrm{pl}}$ computed using $p_{\text {surf }}^{\text {ha }}$ and $1.652 \mathrm{hPa}$ offset is used.

For consistency and a fair comparison with ha and $\mathrm{pl}, \mathrm{hb}$ spectra are also retrieved with the surface pressure input calculated using $p_{\text {surf }}^{\text {ha }}$ and a negative $7.788 \mathrm{hPa}$ offset, given by $66 \mathrm{~m}$ altitude difference. The strong wind could affect the pressure measurement (Bernoulli's equation), which might be the reason for why hb retrieval using its on-site pressure measurements slightly diverges from the result using the pressure data derived from ha weather station data (blue curve in Fig. C1).

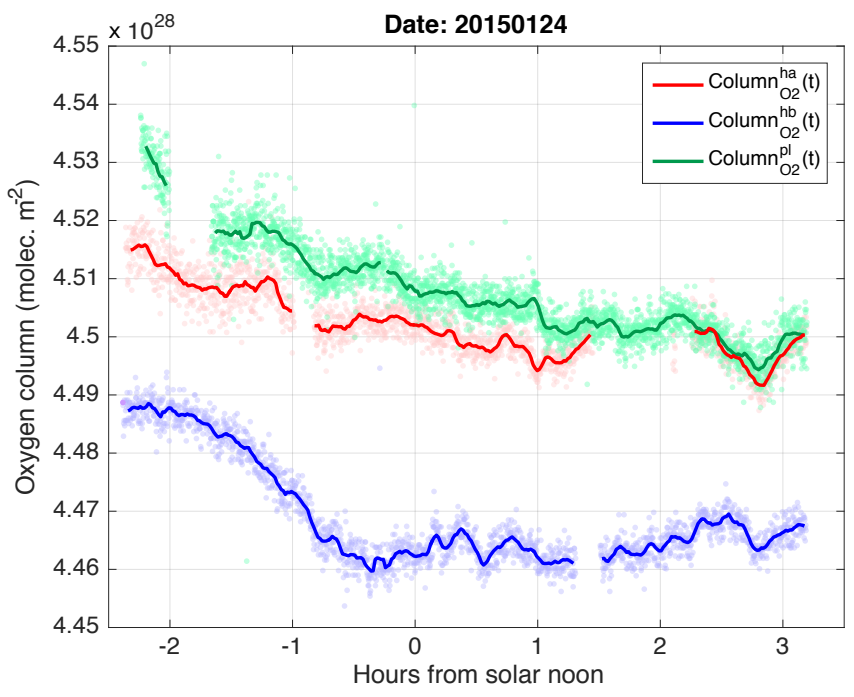

Figure D1. Oxygen column number densities measured by ha, hb, and pl on 24 January 2015.

\section{Appendix D: Dry-air column measurements on 24 January 2015}

Figure D1 shows the ha, hb, and pl measurements of oxygen column number densities. The deviations between three sites and the variations during the course of the day are given by the differences in atmospheric surface pressures and water column number densities. ha and pl measurements are scaled with the factors shown in Table B1 third column.

According to Fig. D1, the oxygen column number density over the dairy area is $4.493 \times 10^{28}$ molec. $\mathrm{m}^{-2} \pm 0.5 \%$, which is used to calculate the column number density of dry air. column $n_{\text {dryair }}$ is needed in the column model (Eq. 4) for the emission estimates. The uncertainty is mainly associated with the differences in altitudes between sites. 


\section{Appendix E: Validation of wind model}

As we have seen, the uncertainties in the wind speed estimates have a significant impact on the emission estimates. Hence, we check our wind model for plausibility in the following by comparing it with ACARS profiles and HYSPLIT simulations.

\section{E1 ACARS profile}

In Fig. E1 we show the automated aircraft reports on profiles measured when taking off and landing at Ontario airport (MADIS ACARS profile data) and the ASOS data to examine the validity of the wind model described in Eq. (12). Two profiles were captured during the FTS measurement period, where only data above $2000 \mathrm{~m}$ a.g.l. are available, and two profiles after the measurement period. For plotting the model, we assume the surface layer height is $z_{\mathrm{S}}=100 \mathrm{~m}$ and the power law exponent $\alpha=1 / 7$.

The potential temperature profiles during the FTS measurements and 2-3 h after are also shown in Fig. E1c and d. For the calculations we use the ACARS temperature profiles and the pressure profiles derived from the barometric formula, the ASOS sea level pressure data and a scale height of $7.4 \mathrm{~km}$. Within the middle portion of the ML, the temperature profile follows adiabatic lapse rate; i.e., the potential temperature is nearly constant with height. This behavior is observed between roughly $200 \mathrm{~m}$ and $800 \mathrm{~m}$ a.g.l. at $2-3 \mathrm{~h}$ after the measurement period. During the FTS measurement period, the airplanes capture data above $2100 \mathrm{~m}$ a.g.l. where the adiabatic process is not observed. Therefore the PBL height is determined to be in the range of 800 to $2100 \mathrm{~m}$ a.g.l. The surface layer is typically the bottom $10 \%$ of the PBL.

\section{E2 HYSPLIT simulation}

We use the HYSPLIT model to calculate the backward trajectories of tracers released from the FTS stations, starting at 20:00 UTC. We determine the wind speed from the traveled distance in $1 \mathrm{~h}$. To obtain a wind speed profile, multiple altitudes for the tracer release were chosen.

The simulated wind speeds are shown in Fig. E2. The blue curve represents the wind speed profile at the upwind site $\mathrm{hb}$, and the red curve represents the wind speed profile at the downwind site ha. The black curve is the average of the two, which gives the mean wind profile.
In addition, the wind profile used in our emission estimate (Eq. 12) is illustrated in Fig. E2 with the grey lines. The lower bound is given by a constant wind speed starting from $10 \mathrm{~m}$ a.g.l., and the upper bound assumes a wind profile power law up to the mixing height $z_{\text {emiss }}$, which is determined as around $200 \mathrm{~m}$ (Eq. 11) using a random-walk model. The wind speed at $10 \mathrm{~m}$ a.g.l. is assumed as the average of KCNO and KONT airports between 19:00 and 20:00 UTC (grey dot, $9.77 \mathrm{~m} \mathrm{~s}^{-1}$ ), which is almost identical to the wind speed at $10 \mathrm{~m}$ a.g.l. determined using HYSPLIT mean (lowest black dot, $9.89 \mathrm{~m} \mathrm{~s}^{-1}$ ).

In Fig. E2, the range given by our wind model covers the mean wind profile determined using the HYSPLIT model (black curve). For the times between 19:00 and 20:00 UTC, $\bar{U}$ is determined as $11.6 \mathrm{~m} \mathrm{~s}^{-1} \pm 15 \%$ using our wind model (Eq. 13), which is consistent with the value of $12.1 \mathrm{~m} \mathrm{~s}^{-1} \mathrm{ob}-$ tained by averaging the HYSPLIT wind profile vertically up to $200 \mathrm{~m}$. 

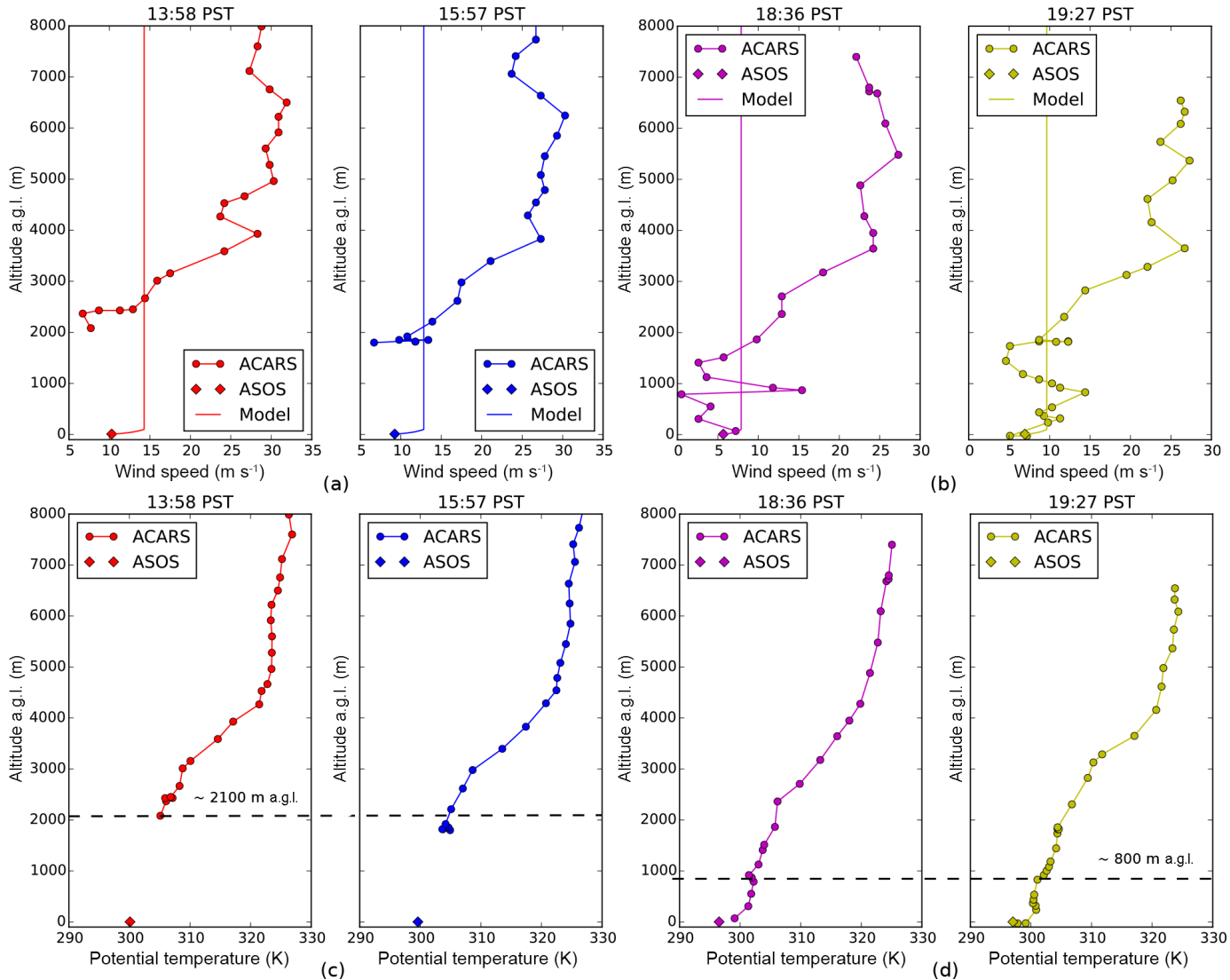

Figure E1. Vertical profile of the horizontal wind speed measurements and the calculated potential temperature profiles, at Ontario airport during (13:58 and 15:57 PST) and after the FTS measurements (18:36 and 19:27 PST), on 24 January 2015.

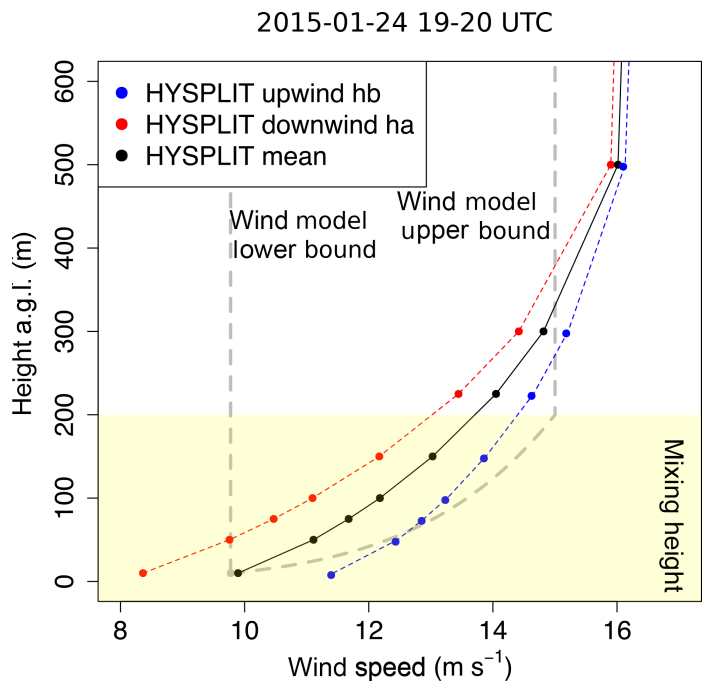

Figure E2. Comparison between our wind model and HYSPLIT simulations of wind speeds at different altitudes. The simulated mean wind profile (black curve) over Chino area is the averaged values of the profiles above the upwind site hb (blue curve) and the downwind site ha (red curve). The grey lines provide the range of our wind model. 

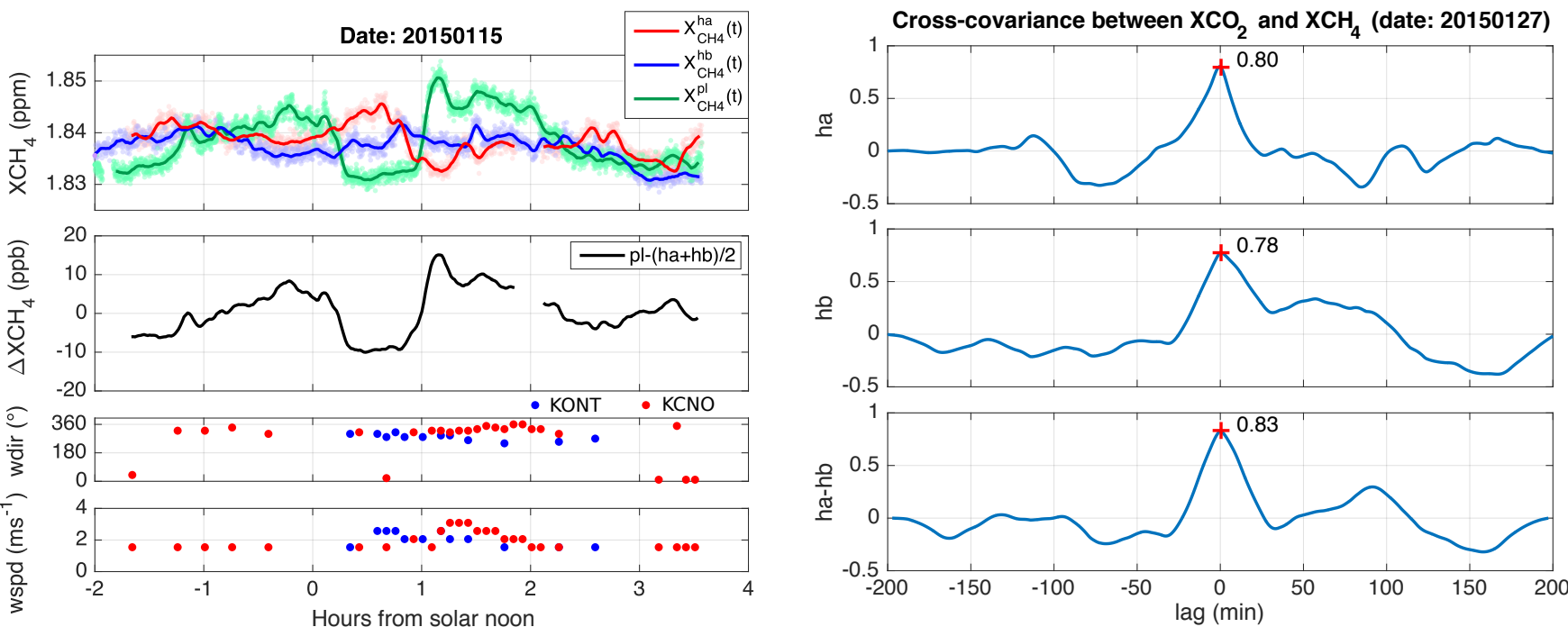

Figure F1. The whole day measurements on 15 January 2015 for $\mathrm{ha}, \mathrm{hb}$ and $\mathrm{pl}$. We neglect the wind measurements with wind speeds reported as zero. Gradient measurements between 1 and $2 \mathrm{~h}$ after solar noon are selected (Fig. 4b) because of the relatively consistent wind speeds and directions at KONT and KCNO.

\section{Appendix F: Column difference measurement on 15 January 2015}

Figure F1 shows the measurements of $X_{\mathrm{CH}_{4}}, \Delta X_{\mathrm{CH}_{4}}$, wind speeds, and wind directions for the entire day. For verifying the simple column model, we select the time period between 1 and $2 \mathrm{~h}$ after solar noon with relatively consistent wind speeds and directions at KONT and KCNO. The data for the selected time window are shown in Fig. $4 \mathrm{~b}$.

Figure G1. The cross covariance function (mean-removed cross correlation) between $X_{\mathrm{CH}_{4}}$ and $X_{\mathrm{CO}_{2}}$ for individual sites measured with ha and hb are shown in first and second panels. The lagged cross covariance between $\Delta X_{\mathrm{CH}_{4}}$ and $\Delta X_{\mathrm{CO}_{2}}$ (third panel) has a larger value at zero lag compared to the first and second panels.

\section{Appendix G: Cross covariance function between the $X_{\mathrm{CH}_{4}}$ and $X_{\mathrm{CO}_{2}}$ on 27 January 2015}

Shown in Fig. G1 are the lagged cross covariance between $X_{\mathrm{CH}_{4}}$ and $X_{\mathrm{CO}_{2}}$ for individual sites measured with ha and $\mathrm{hb}$ and between $\Delta X_{\mathrm{CH}_{4}}$ and $\Delta X_{\mathrm{CO}_{2}}$. 


\section{Appendix H: Lidar measurement in Boston}

Figure $\mathrm{H} 1$ shows the NRB signal recorded using a mini micro pulse lidar (MiniMPL from company Sigma Space) on the roof of Boston University on 16 April 2015. We integrate the NRB signal vertically from 0 to $1.5 \mathrm{~km}$ a.g.l. to obtain the mean NRB. The time series of the mean NRB together with our FTS measurements are shown in Fig. 9.

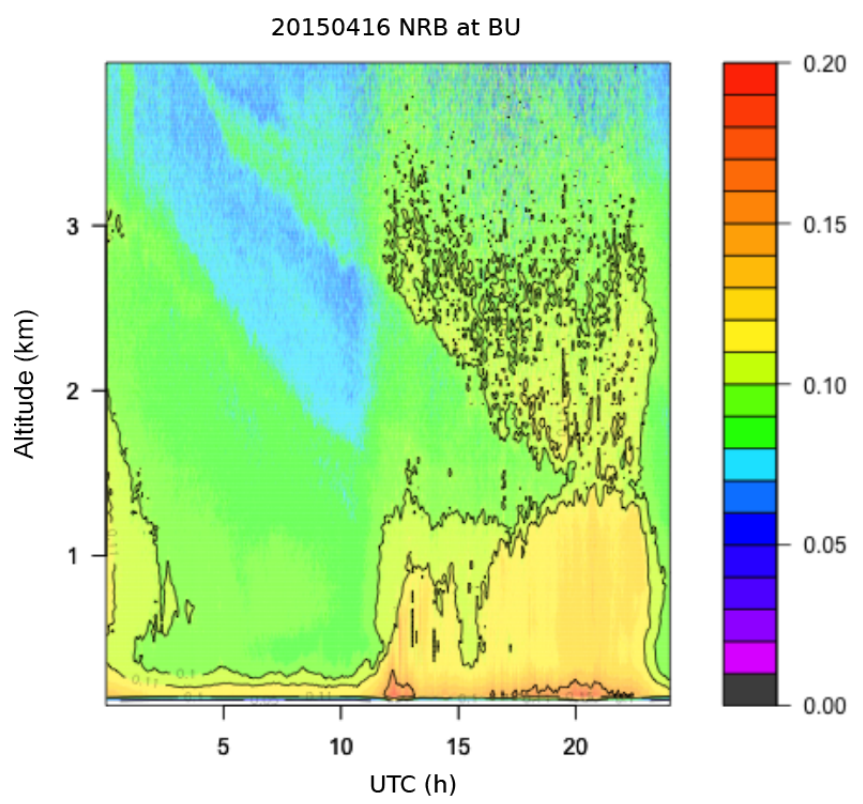

Figure H1. Lidar measurement on the roof of Boston University on 16 April 2015. 
Acknowledgements. We thank Bruce Daube and John Budney for the preparation of the measurement campaign in Chino and Pasadena and for building the weather stations and the enclosures for the spectrometers. We thank Frank Hase for help with the PROFFIT retrieval software, Matthias Frey for instructions on the ILS measurements, and Matthäus Kiel for the Calpy software. We thank Yanina Barrera for the lidar data and Frank Hase, Kelly Chance, Christoph Gerbig, Bruce Daube, John Budney, Bill Munger, Rachel Chang, and Kathryn McKain for fruitful discussions. Funding for this study was provided by the National Science Foundation through Major Research Instrumentation Award 1337512 "Acquisition of Mesoscale Network of Surface Sensors and Solar-tracking Spectrometers". Jia Chen was partly supported by Technische Universität München - Institute for Advanced Study, funded by the German Excellence Initiative and the European Union Seventh Framework Programme under grant agreement no. 291763. Harrison Parker and Manvendra K. Dubey (Los Alamos National Laboratory) acknowledge NASA's Carbon Monitoring Program for funding the EM27/SUN application development. The authors gratefully acknowledge the NOAA Air Resources Laboratory (ARL) for the provision of the HYSPLIT transport and dispersion model. The authors would also like to thank the anonymous reviewers for helpful comments.

This work was supported by the German Research

Foundation (DFG) and the Technische Universität

München within the funding programme

Open Access Publishing.

Edited by: M. Heimann

\section{References}

Allan, D. W.: Statistics of atomic frequency standards, Proceedings of the IEEE, 54, 221-230, 1966.

Bréon, F. M., Broquet, G., Puygrenier, V., Chevallier, F., XuerefRemy, I., Ramonet, M., Dieudonné, E., Lopez, M., Schmidt, M., Perrussel, O., and Ciais, P.: An attempt at estimating Paris area $\mathrm{CO}_{2}$ emissions from atmospheric concentration measurements, Atmos. Chem. Phys., 15, 1707-1724, doi:10.5194/acp-15-17072015, 2015.

Bruker: IFS 125HR User Manual, BRUKER OPTIK GmbH, 1st Edn., 2006.

Cambaliza, M. O. L., Shepson, P. B., Caulton, D. R., Stirm, B., Samarov, D., Gurney, K. R., Turnbull, J., Davis, K. J., Possolo, A., Karion, A., Sweeney, C., Moser, B., Hendricks, A., Lauvaux, T., Mays, K., Whetstone, J., Huang, J., Razlivanov, I., Miles, N. L., and Richardson, S. J.: Assessment of uncertainties of an aircraft-based mass balance approach for quantifying urban greenhouse gas emissions, Atmos. Chem. Phys., 14, 9029-9050, doi:10.5194/acp-14-9029-2014, 2014.

Chang, R. Y.-W., Miller, C. E., Dinardo, S. J., Karion, A., Sweeney, C., Daube, B. C., Henderson, J. M., Mountain, M. E., Eluszkiewicz, J., Miller, J. B., Bruhwiler, L. M. P., and Wofsy, S. C.: Methane emissions from Alaska in 2012 from CARVE airborne observations, Proc. Natl. Acad. Sci. USA, 111, 1669416699, 2014.
Chen, J., Wofsy, S. C., Franklin, J. E., Jones, T., Gottlieb, E. W., Parker, H., Dubey, M. K., Hedelius, J. K., Viatte, C., and Wennberg, P. O.: Replication Data for "Differential Column Measurements Using Compact Solar-Tracking Spectrometers", doi:10.7910/DVN/J2YPX3, 2016.

Crisp, D., Miller, C. E., and DeCola, P. L.: NASA Orbiting Carbon Observatory: measuring the column averaged carbon dioxide mole fraction from space, J. Appl. Remote Sens., 2, 023508 023508, doi:10.1117/1.2898457, 2008.

Davis, S. P., Abrams, M. C., and Brault, J. W.: Fourier transform spectrometry, Academic Press, 2001.

Draxler, R. R. and Hess, G.: An overview of the HYSPLIT_4 modelling system for trajectories, Aust. Meteorol. Mag., 47, 295308, 1998.

EDF: Natural gas: Local leaks impact global climate, available at: https://www.edf.org/climate/methanemaps, last access: 22 May 2016.

Frankenberg, C., Pollock, R., Lee, R. A. M., Rosenberg, R., Blavier, J.-F., Crisp, D., O’Dell, C. W., Osterman, G. B., Roehl, C., Wennberg, P. O., and Wunch, D.: The Orbiting Carbon Observatory (OCO-2): spectrometer performance evaluation using prelaunch direct sun measurements, Atmos. Meas. Tech., 8, 301313, doi:10.5194/amt-8-301-2015, 2015.

Frey, M., Hase, F., Blumenstock, T., Groß, J., Kiel, M., Mengistu Tsidu, G., Schäfer, K., Sha, M. K., and Orphal, J.: Calibration and instrumental line shape characterization of a set of portable FTIR spectrometers for detecting greenhouse gas emissions, Atmos. Meas. Tech., 8, 3047-3057, doi:10.5194/amt-8-3047-2015, 2015.

Fu, D., Pongetti, T. J., Blavier, J.-F. L., Crawford, T. J., Manatt, K. S., Toon, G. C., Wong, K. W., and Sander, S. P.: Near-infrared remote sensing of Los Angeles trace gas distributions from a mountaintop site, Atmos. Meas. Tech., 7, 713-729, doi:10.5194/amt7-713-2014, 2014.

Gisi, M., Hase, F., Dohe, S., and Blumenstock, T.: Camtracker: a new camera controlled high precision solar tracker system for FTIR-spectrometers, Atmos. Meas. Tech., 4, 47-54, doi:10.5194/amt-4-47-2011, 2011.

Gisi, M., Hase, F., Dohe, S., Blumenstock, T., Simon, A., and Keens, A.: $\mathrm{XCO}_{2}$-measurements with a tabletop FTS using solar absorption spectroscopy, Atmos. Meas. Tech., 5, 2969-2980, doi:10.5194/amt-5-2969-2012, 2012.

Griffiths, P. R. and De Haseth, J. A.: Fourier transform infrared spectrometry, vol. 171, John Wiley \& Sons, 2007.

Grimm, N. B., Faeth, S. H., Golubiewski, N. E., Redman, C. L., Wu, J., Bai, X., and Briggs, J. M.: Global change and the ecology of cities, Science, 319, 756-760, 2008.

Gurney, K. R., Romero-Lankao, P., Seto, K. C., Hutyra, L. R., Duren, R., Kennedy, C., Grimm, N. B., Ehleringer, J. R., Marcotullio, P., Hughes, S., Pincetl, S., Chester, M. V., Runfola, D. M., J., F. J., and Sperling, J.: Climate change: Track urban emissions on a human scale, Nature, 525, 179-181, 2015.

Hannigan, J. W.: NDACC IRWG: Evolution of Ground-Based Global Trace Gas Infrared Remote Sensing, in: Fourier Transform Spectroscopy, p. FMC1, Optical Society of America, 2011.

Hase, F., Blumenstock, T., and Paton-Walsh, C.: Analysis of the instrumental line shape of high-resolution Fourier transform IR spectrometers with gas cell measurements and new retrieval soft- 
ware, Appl. Optics, 38, 3417-3422, doi:10.1364/AO.38.003417, 1999.

Hase, F., Hannigan, J., Coffey, M., Goldman, A., Höpfner, M., Jones, N., Rinsland, C., and Wood, S.: Intercomparison of retrieval codes used for the analysis of high-resolution, groundbased FTIR measurements, J. Quant. Spectrosc. Ra., 87, 25-52, 2004.

Hase, F., Frey, M., Blumenstock, T., Groß, J., Kiel, M., Kohlhepp, R., Mengistu Tsidu, G., Schäfer, K., Sha, M. K., and Orphal, J.: Application of portable FTIR spectrometers for detecting greenhouse gas emissions of the major city Berlin, Atmos. Meas. Tech., 8, 3059-3068, doi:10.5194/amt-8-3059-2015, 2015.

Hedelius, J. K., Viatte, C., Wunch, D., Roehl, C., Toon, G. C., Chen, J., Jones, T., Wofsy, S. C., Franklin, J. E., Parker, H., Dubey, M. K., and Wennberg, P. O.: Assessment of errors and biases in retrievals of $\mathrm{X}_{\mathrm{CO} 2}, \mathrm{X}_{\mathrm{CH} 4}, \mathrm{X}_{\mathrm{CO}}$, and $\mathrm{X}_{\mathrm{N}_{2} \mathrm{O}}$ from a $0.5 \mathrm{~cm}^{-1}$ resolution solar viewing spectrometer, Atmos. Meas. Tech. Discuss., doi:10.5194/amt-2016-39, in review, 2016.

Hsu, S., Meindl, E. A., and Gilhousen, D. B.: Determining the power-law wind-profile exponent under near-neutral stability conditions at sea, J. Appl. Meteorol., 33, 757-765, 1994.

Jacob, D.: Introduction to atmospheric chemistry, Princeton University Press, 1999.

Klappenbach, F., Bertleff, M., Kostinek, J., Hase, F., Blumenstock, T., Agusti-Panareda, A., Razinger, M., and Butz, A.: Accurate mobile remote sensing of $\mathrm{XCO}_{2}$ and $\mathrm{XCH}_{4}$ latitudinal transects from aboard a research vessel, Atmos. Meas. Tech., 8, 50235038, doi:10.5194/amt-8-5023-2015, 2015.

Kort, E. A., Frankenberg, C., Miller, C. E., and Oda, T.: Space-based observations of megacity carbon dioxide, Geophys. Res. Lett., 39, L17806, doi:10.1029/2012GL052738, 2012.

Kort, E. A., Frankenberg, C., Costigan, K. R., Lindenmaier, R., Dubey, M. K., and Wunch, D.: Four corners: The largest US methane anomaly viewed from space, Geophys. Res. Lett., 41, 6898-6903, 2014.

Lindenmaier, R., Dubey, M. K., Henderson, B. G., Butterfield, Z. T., Herman, J. R., Rahn, T., and Lee, S.-H.: Multiscale observations of $\mathrm{CO}_{2},{ }^{13} \mathrm{CO}_{2}$, and pollutants at Four Corners for emission verification and attribution, Proc. Natl. Acad. Sci., 111, 8386-8391, 2014.

McCrea, W. and Whipple, F.: Random Paths in Two and Three Dimensions, Proc. R. Soc. Edin., 60, 281-298, 1940.

McKain, K., Wofsy, S. C., Nehrkorn, T., Eluszkiewicz, J., Ehleringer, J. R., and Stephens, B. B.: Assessment of groundbased atmospheric observations for verification of greenhouse gas emissions from an urban region, Proc. Natl. Acad. Sci., 109, 8423-8428, 2012.

Mellqvist, J., Samuelsson, J., Johansson, J., Rivera, C., Lefer, B., Alvarez, S., and Jolly, J.: Measurements of industrial emissions of alkenes in Texas using the solar occultation flux method, J. Geophys. Res., 115, D00F17, doi:10.1029/2008JD011682, 2010.

Peischl, J., Ryerson, T. B., Brioude, J., Aikin, K. C., Andrews, A. E., Atlas, E., Blake, D., Daube, B. C., de Gouw, J. A., Dlugokencky, E., Frost, G. J., Gentner, D. R., Gilman, J. B., Goldstein, A. H., Harley, R. A., Holloway, J. S., Kofler, J., Kuster, W. C., Lang, P. M., Novelli, P. C., Santoni, G. W., Trainer, M., Wofsy, S. C., and Parrish, D. D.: Quantifying sources of methane using light alkanes in the Los Angeles basin, California, J. Geophys. Res.Atmos., 118, 4974-4990, 2013.
Picarro G2301 CRDS Analyzer for $\mathrm{CO}_{2} \mathrm{CH}_{4} \mathrm{H}_{2} \mathrm{O}$ Measurements in Air, available at: https://picarro.box.com/shared/static/ dzibhjqlmbw81pfpa838fbs8kck6it9q.pdf (last access: 2 July 2016) 2015a.

Picarro $\mathrm{G} 2401 \mathrm{CO}_{2}+\mathrm{CO}+\mathrm{CH}_{4}+\mathrm{H}_{2} \mathrm{O}$ CRDS Analyzer, available at: https://picarro.box.com/shared/static/ vfh80atc42tnq04t4a996t8sestqov9x.pdf (last access: 2 July 2016) $2015 b$.

Stein, A., Draxler, R., Rolph, G., Stunder, B., Cohen, M., and Ngan, F.: NOAA's HYSPLIT atmospheric transport and dispersion modeling system, B. Ame. Meteorol. Soc., 96, 2059-2077, 2015.

Stremme, W., Ortega, I., and Grutter, M.: Using ground-based solar and lunar infrared spectroscopy to study the diurnal trend of carbon monoxide in the Mexico City boundary layer, Atmos. Chem. Phys., 9, 8061-8078, doi:10.5194/acp-9-8061-2009, 2009.

Stremme, W., Grutter, M., Rivera, C., Bezanilla, A., Garcia, A. R., Ortega, I., George, M., Clerbaux, C., Coheur, P.-F., Hurtmans, D., Hannigan, J. W., and Coffey, M. T.: Top-down estimation of carbon monoxide emissions from the Mexico Megacity based on FTIR measurements from ground and space, Atmos. Chem. Phys., 13, 1357-1376, doi:10.5194/acp-13-1357-2013, 2013.

Stull, R. B.: An introduction to boundary layer meteorology, vol. 13, Springer Science \& Business Media, 1988.

Taylor, G. I.: The spectrum of turbulence, in: Proceedings of the Royal Society of London A: Mathematical, Physical and Engineering Sciences, 164, 476-490, The Royal Society, 1938.

Té, Y., Dieudonné, E., Jeseck, P., Hase, F., Hadji-Lazaro, J., Clerbaux, C., Ravetta, F., Payan, S., Pépin, I., Hurtmans, D., Pelon, J., and Camy-Peyret, C.: Carbon monoxide urban emission monitoring: A ground-based FTIR case study, J. Atmos. Ocean. Tech., 29, 911-921, 2012.

Toon, G., Blavier, J.-F., Washenfelder, R., Wunch, D., KeppelAleks, G., Wennberg, P., Connor, B., Sherlock, V., Griffith, D., Deutscher, N., and Notholt, J.: Total column carbon observing network (TCCON), in: Fourier Transform Spectroscopy, p. JMA3, Optical Society of America, 2009.

Veefkind, J., Aben, I., McMullan, K., Förster, H., de Vries, J., Otter, G., Claas, J., Eskes, H., de Haan, J., Kleipool, Q., van Weele, M., Hasekamp, O., Hoogeveen, R., Landgraf, J., Snel, R., Tol, P., Ingmann, P., Voors, R., Kruizinga, B., Vink, R., Visser, H., and Levelt, P. : TROPOMI on the ESA Sentinel-5 Precursor: A GMES mission for global observations of the atmospheric composition for climate, air quality and ozone layer applications, Remote Sens. Environ., 120, 70-83, 2012.

Viatte, C., Lauvaux, T., Hedelius, J. K., Parker, H., Chen, J., Jones, T., Franklin, J. E., Deng, A. J., Gaudet, B., Verhulst, K., Duren, R., Wunch, D., Roehl, C., Dubey, M. K., Wofsy, S., and Wennberg, P. O.: Methane emissions from dairies in the Los Angeles Basin, Atmos. Chem. Phys. Discuss., doi:10.5194/acp2016-281, in review, 2016.

Wennberg, P. O., Mui, W., Wunch, D., Kort, E. A., Blake, D. R., Atlas, E. L., Santoni, G. W., Wofsy, S. C., Diskin, G. S., Jeong, S., and Fischer, M. L.: On the sources of methane to the Los Angeles atmosphere, Environ. Sci. Technol., 46, 9282-9289, 2012.

Wennberg, P. O., Wunch, D., Roehl, C., Blavier, J.-F., Toon, G. C., and Allen, N.: TCCON data from California Institute of Technology, Pasadena, California, USA, Release GGG2014R1, TCCON data archive, hosted by the Carbon Dioxide Information Analysis 
Center, Oak Ridge National Laboratory, Oak Ridge, Tennessee, USA, doi:10.14291/tccon.ggg2014.pasadena01.R1/1182415, 2014.

Werle, P., Mücke, R., and Slemr, F.: The limits of signal averaging in atmospheric trace-gas monitoring by tunable diode-laser absorption spectroscopy (TDLAS), Appl. Phys. B, 57, 131-139, 1993.

WHO: available at: http://www.who.int/gho/urban_health/ situation_trends/urban_population_growth_text (last access: 28 October 2015), 2014.

Wong, K. W., Fu, D., Pongetti, T. J., Newman, S., Kort, E. A., Duren, R., Hsu, Y.-K., Miller, C. E., Yung, Y. L., and Sander, S. P.: Mapping $\mathrm{CH}_{4}: \mathrm{CO}_{2}$ ratios in Los Angeles with CLARSFTS from Mount Wilson, California, Atmos. Chem. Phys., 15, 241-252, doi:10.5194/acp-15-241-2015, 2015.

Wunch, D., Wennberg, P. O., Toon, G. C., Keppel-Aleks, G., and Yavin, Y. G.: Emissions of greenhouse gases from a North American megacity, Geophys. Res. Lett., 36, L15810, doi:10.1029/2009GL039825, 2009.

Wunch, D., Toon, G. C., Wennberg, P. O., Wofsy, S. C., Stephens, B. B., Fischer, M. L., Uchino, O., Abshire, J. B., Bernath, P., Biraud, S. C., Blavier, J.-F. L., Boone, C., Bowman, K. P., Browell, E. V., Campos, T., Connor, B. J., Daube, B. C., Deutscher, N. M., Diao, M., Elkins, J. W., Gerbig, C., Gottlieb, E., Griffith, D. W. T., Hurst, D. F., Jiménez, R., Keppel-Aleks, G., Kort, E. A., Macatangay, R., Machida, T., Matsueda, H., Moore, F., Morino, I., Park, S., Robinson, J., Roehl, C. M., Sawa, Y., Sherlock, V., Sweeney, C., Tanaka, T., and Zondlo, M. A.: Calibration of the Total Carbon Column Observing Network using aircraft profile data, Atmos. Meas. Tech., 3, 1351-1362, doi:10.5194/amt3-1351-2010, 2010.
Wunch, D., Toon, G. C., Blavier, J. F., Washenfelder, R. A., Notholt, J., Connor, B. J., Griffith, D. W., Sherlock, V., and Wennberg, P. O.: The total carbon column observing network, Philos. Trans. A Math. Phys. Eng. Sci., 369, 2087-112, 2011.

Wunch, D., Toon, G. C., Sherlock, V., Deutscher, N. M., Liu, X., Feist, D. G., and Wennberg, P. O.: The Total Carbon Column Observing Network's GGG2014 Data Version, Carbon Dioxide Information Analysis Center, Oak Ridge National Laboratory, Oak Ridge, Tennessee, USA, 10, doi:10.14291/tccon.ggg2014.documentation.R0/1221662, 2015.

York, D., Evensen, N. M., Martınez, M. L., and Delgado, J. D. B.: Unified equations for the slope, intercept, and standard errors of the best straight line, Am. J. Phys., 72, 367-375, 2004. 